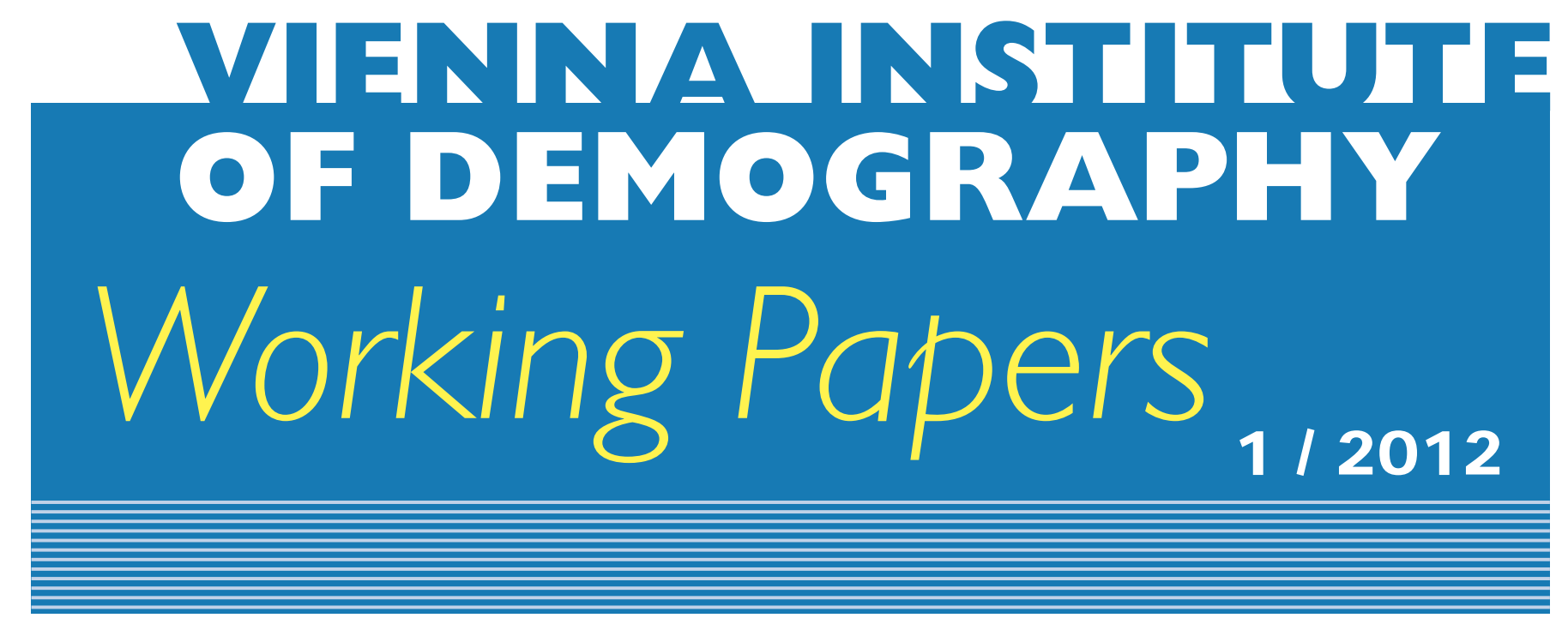

Guy J. Abel

\title{
Estimating Global Migration Flow Tables Using Place of Birth Data
}

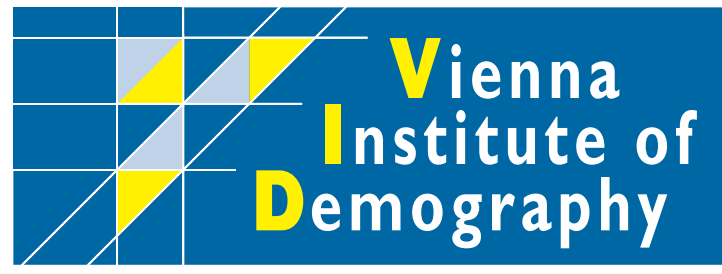

Vienna Institute of Demography Austrian Academy of Sciences

Wohllebengasse 12-14

A-I040Vienna $\cdot$ Austria

E-Mail:vid@oeaw.ac.at

Website: www.oeaw.ac.at/vid 


\begin{abstract}
A methodology to estimate global migration flow tables of transitions between all countries is illustrated in two parts. First, a methodology to derive flows from sequential stock tables is developed. Second, the methodology is applied to recently released World Bank migration stock tables between 1960 and 2000 (Özden, 2011) to estimate a set of four de'cadal global migration flow tables. The results of the applied methodology are discussed with reference to comparable estimates of global net migration flows of the United Nations and models for international migration flows. The proposed methodology adds to the limited previous literature on linking migration flows to stocks. The estimated flow tables represent a first-of-a-kind set of comparable global origin destination flow data.
\end{abstract}

\title{
Keywords
}

Migration estimation, International migration flows, International migration stocks, conditional maximisation, log-linear model with offset.

\section{Author}

Guy J. Abel, Research Scientist, Wittgenstein Centre (IIASA, VID/OAW, WU), Vienna Institute of Demography/Austrian Academy of Sciences. Email: guy.abel@oeaw.ac.at

\section{Acknowledgements}

I would like to thank James Raymer and Nikola Sander for their comments and suggestions on an earlier version of this paper and Joel Cohen for his recommendations concerning the validation exercises. 


\section{Estimating Global Migration Flow Tables Using Place of Birth Data}

Guy J. Abel

\section{Introduction}

International moves are typically enumerated in a demographic context using either a measurement of migrant stocks or migration flows. A migrant stock is defined as the total number of international migrants present in a given country at a particular point of time. A migration flow is defined as the number of persons arriving or leaving a given country over the course of a specific period of time. Flow measures reflect the dynamics of the migration process and are typically considered less tractable than stock measures (Bilsborrow et al., 1997, p.51).

International migration flow data often lacks adequate measurements of volumes, direction and completeness (Kelly, 1987; Salt, 1993; Willekens, 1994; Nowok et al., 2006), making cross national comparisons difficult. The lack of comparability in flow data can be traced to a number of causes. First, migration is a multi-dimensional process (Goldstein, 1976) involving a transition between two states. Consequently, movements can be reported by sending or receiving countries. When data collection methods or measurements used in these countries differ, the reported counts do not match. Second, international migration flow data are typically collected by individual national statistics institutes in each country, where measures have been designed to solely suit domestic priorities. Data are often produced within a legal framework, and hence alterations to their collection are difficult to implement. Finally, in many countries, migration data collection systems do not exist. In other countries, collection methods (such as passenger surveys) may provide inadequate means to report flows at the levels of detail required by some data users.

This paper aims to circumnavigate these difficulties by developing a methodology to derive bilateral migration flows from sequential stock tables. Basing estimated migration flows upon stocks has a number of potential advantages. First, bilateral migration flow tables may be considered as part of a wider account of demographic data. Rees (1980) noted that national account statistics of financial stocks and flows have served economists well in their modelling activities, encouraging users to compare data for consistencies, check for inadequacies and force analysts to attempt to match available data with a conceptual model. He followed, a similar system of demographic accounts in migration stocks and flows would likely lead to similar improvements. Second, stock data are, in comparison to international migration flow data, far easier to measure. Stock data are more widely available, both across time and countries. This is reflected in the World Bank migration stock data which include bilateral records from over 200 nations and four decades (Özden et al., 2011). In comparison, the 2010 revision of bilateral international migration flow data released by the United Nations (Henning and Hovy, 
2011) covers only 43, predominately developed world countries, from the last two decades. The greater availability of migrant stock data makes it an invaluable source of information on migrant patterns that, as illustrated in the methodological section of this paper, can be used as a basis to estimate global bilateral migration flow tables.

Estimates of global bilateral flow tables can potentially have a number of advantages over presently available international migration data. First, they allow a fuller understanding of population behaviour and change in comparison to other measures of migration. Studying migration using both origin and destination dimensions furthers the possibility of deeper insights into migration patterns and migrant behaviours. Such insights can be confounded by more conventional methods of analysis on existing measures of migration flows, such as those to or from only a few select nations or through the study of net migration. Second, bilateral migration flow tables allow a comparison of migration propensities across multiple countries. Consequently, the contributions made by each nation to the global system of migration can be more easily identified, and comparative summaries of migration flows become more meaningful in a multinational context. Third, estimates of bilateral migration flow tables permits a more comprehensive empirical source for the testing of migration theories. In addition, the study of public policies towards the control or encouragement of migration flows can be further expanded to incorporate a wider evidence base. Fourth, estimates of international migration flow tables can provide a more perceptive base data for global population forecasts. Current global population forecasts, such as K.C. et al. (2010) or United Nations Population Division (2011) utilise only estimated international net migration totals, where no other comparable migration data exists for population forecasters on such scales (Kupiszewski and Kupiszewska, 2008). As such, global forecasting exercise often run the risk of well documented problems of using net migration measures in their models, see for example Rogers $(1990,1995)$. These potential benefits are leading international organisations to call for the promotion and development of methodologies for the collection and processing of internationally comparable statistical data on international migration (United Nations General Assembly, 2011).

There is a limited previous literature on linking migration flows to stocks. Rogers and von Rabenau (1971) and Rogers and Raymer (2005) focused on US Census place of birth data to estimate inter-state migration transitions. The first of these papers relies on a simplistic principal assumption of equal growth of stock totals in all regions. This assumption is unrealistic when comparing data from multiple countries and is likely to produce many erroneous (including negative) estimates of migration flows. The second of these papers relies on a very detailed disaggregation of stock data, that usually unavailable for international migration data.

In this paper, a new methodology to estimate global migration flow tables of transitions between all countries is illustrated in two parts. First, a methodology to derive flows from sequential stock tables is developed. Using a set of simple hypothetical data rather than a full global matrix, the methodology is initially demonstrated in a scenario where there are no births and deaths in migrant stock populations between two periods. An extension for natural changes in population totals is then shown. Estimation is undertaken using a spatial interaction model, equivalent to a log-linear model in statistics. Such methods have a developed literature in the indirect estimation of internal migration flows, where marginal totals (immigration and emigration flows into and out of a set of regions) are known, but the table contents is missing 
(Fotheringham and O'Kelly, 1988; Willekens, 1999). Second, the methodology is applied to recently released World Bank migration stock tables between 1960 and 2000 (Özden et al., 2011) to estimate a set of four de'cadal global migration flow tables. Summary results of the applied methodology are first presented and then discussed with reference to comparable estimates of global net migration flows of the United Nations and models for international migration. These validation exercises give an indication of the performance of the applied methodology. In the final section, potential extensions are outlined and conclusions given.

\section{Methodology}

A general methodology for estimation of migration flows from sequential migrant stock tables is derived in this section. The estimation of migration flows between a set of regions are illustrated using a set of simple hypothetical data. Increasing complexity is added to account for additional factors that might also effect changes in stock totals, besides migration flows, such as births, deaths and movements to and from external regions not considered.

Bilateral migration data is commonly represented in square tables. Values within the table vary, depending on definitions used in data collection or the research question at hand. Values in non-diagonal cells represent some form of movement, for example a migration flow or a foreign born stock between a specified set of $R$ regions or areas. Values in diagonal cells represent some form non-moving population, or those that move within a region, and are sometimes not presented.

Consider two migrant stock tables in consecutive years $(t$ and $t+1)$ in the top panel of Table 1. Regions A to D represent places of birth in the rows, and place of residence in the columns. Hence, non-diagonal entries represent the number of foreign born migrants in each area of residence, whilst diagonal entries contain the number of native born residents.

In this hypothetical example there are no births or deaths. This results in two noticeable features in the tables. First, the row totals in each time period remain the same, as the number people born in each region can not increase or decrease. Second, differences in cells must implicitly be driven solely by migration. These migrations occurs by individuals changing their place of residence (moving across columns), whilst their place of birth (row) characteristic remains fixed.

To derive a corresponding set of flows that are constrained to meet the stocks tables, we can alternatively consider the top panel of a Table 1 as a set of $R$ birth place specific migration flow tables where the marginal totals are known, shown in the bottom panel of Table 1 . These are formed by considering each row of the two consecutive stock tables as a set of separate margins of a migration flow table. Place of residence totals at time $t$ from the stock data now become origin margin (row) totals for each birth place specific population. Similarly, place of residence totals at time $t+1$ from the stock data now become destination margin (column) totals for each birth place specific population. As the row totals from the stock tables were equal, the row and column margins in each of the birth place specific migration flow tables in Table 1 are also equal.

Conceptually there are several different ways data can be estimated (or collected) on the relocation from one permanent place of residence to anther, which can yield to different counts 
Table 1: Dummy Example of Place of Birth Migrant Stock Data

Place of Birth Data in Stock Tables:

\begin{tabular}{|c|c|c|c|c|c|c|c|c|c|c|c|c|c|}
\hline & \multicolumn{6}{|c|}{ Place of Residence ( $t$ ) } & & \multicolumn{6}{|c|}{ Place of Residence $(t+1)$} \\
\hline \multirow{6}{*}{ 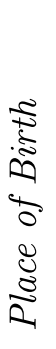 } & & $\mathrm{A}$ & B & $\mathrm{C}$ & $\mathrm{D}$ & Sum & \multirow{6}{*}{ 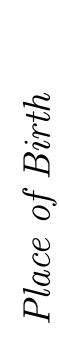 } & & $\mathrm{A}$ & $\mathrm{B}$ & $\mathrm{C}$ & $\mathrm{D}$ & Sum \\
\hline & $\mathrm{A}$ & 1000 & 100 & 10 & 0 & 1110 & & $\mathrm{~A}$ & 950 & 100 & 60 & 0 & 1110 \\
\hline & $\mathrm{B}$ & 55 & 555 & 50 & 5 & 665 & & B & 80 & 505 & 75 & 5 & 665 \\
\hline & $\mathrm{C}$ & 80 & 40 & 800 & 40 & 960 & & C & 90 & 30 & 800 & 40 & 960 \\
\hline & $\mathrm{D}$ & 20 & 25 & 20 & 200 & 265 & & $\mathrm{D}$ & 40 & 45 & 0 & 180 & 265 \\
\hline & Sum & 1155 & 720 & 880 & 245 & 3000 & & Sum & 1160 & 680 & 935 & 225 & 3000 \\
\hline
\end{tabular}

Place of Birth Data in Flow Tables:

\begin{tabular}{|c|c|c|c|c|c|c|c|c|c|c|c|c|c|}
\hline \multicolumn{7}{|c|}{ Place of Birth $=A$} & \multicolumn{7}{|c|}{ Place of Birth $=B$} \\
\hline & & \multicolumn{4}{|c|}{ Destination } & & & \multicolumn{6}{|c|}{ Destination } \\
\hline & & A & B & $\mathrm{C}$ & $\mathrm{D}$ & Sum & & & A & B & $\mathrm{C}$ & $\mathrm{D}$ & Sum \\
\hline \multirow{5}{*}{ క్ } & $\mathrm{A}$ & & & & & 1000 & \multirow{4}{*}{ हొ } & A & & & & & 55 \\
\hline & $\mathrm{B}$ & & & & & 100 & & B & & & & & 555 \\
\hline & $\mathrm{C}$ & & & & & 10 & & $\mathrm{C}$ & & & & & 50 \\
\hline & $\mathrm{D}$ & & & & & 0 & & $\mathrm{D}$ & & & & & 5 \\
\hline & Sum & 950 & 100 & 60 & 0 & 1110 & & Sum & 80 & 505 & 75 & 5 & 665 \\
\hline
\end{tabular}

Place of Birth $=C$

Place of Birth $=D$

Destination

Destination

\begin{tabular}{|c|c|c|c|c|c|c|c|c|c|c|c|c|}
\hline & $\mathrm{A}$ & B & $\mathrm{C}$ & $\mathrm{D}$ & Sum & \multirow{6}{*}{$\begin{array}{l}\text { ह్స్ } \\
\text { క్ }\end{array}$} & & $\mathrm{A}$ & B & $\mathrm{C}$ & $\mathrm{D}$ & Sum \\
\hline $\mathrm{A}$ & & & & & 80 & & $\mathrm{~A}$ & & & & & 20 \\
\hline B & & & & & 40 & & B & & & & & 25 \\
\hline $\mathrm{C}$ & & & & & 800 & & $\mathrm{C}$ & & & & & 20 \\
\hline $\mathrm{D}$ & & & & & 40 & & $\mathrm{D}$ & & & & & 200 \\
\hline Sum & 90 & 30 & 800 & 40 & 960 & & Sum & 40 & 45 & 0 & 180 & 265 \\
\hline
\end{tabular}

for the same flow, see for example Rees and Willekens (1986). Within each birth place specific table in the bottom panel of Table 1, missing non-diagonal cells must represent the migrant transition flows from origin $i$ to destination $j$, within time period $t$ to $t+1$ and categorised by birth-place $k$. Missing diagonal entries represent the number of non-movers between the $t$ and $t+1$. In order to estimate the missing migrant transition flows and non-movers, model based methods are used to impute values that are constrained to the known marginal totals.

Flowerdew (1991) outlined two main approaches for the use of models to analyse or estimate flow tables for internal migration data: the gravity model and the spatial interaction model. The gravity model approach derives from movements between regions in a similar manner to particle responses to two gravitational masses, as proposed by Newton in Principia Mathematica. Stewart (1941) and Zipf (1942) framed this approach for migration data, relying on 
statistical estimation of migration volumes, given information on each origin, destination and a measurement of association between them. The spatial interaction models, associated with Wilson (1970) are based on mathematical algorithms to calibrate a constrained model to origin and destination totals. There are numerous formulations of spatial interaction models such as bi-proportional adjustment, information gain minimizing and entropy maximizing which include various constraints and interaction terms (Willekens, 1983).

Poisson regression models have become a popular method for representing migration models as they relate gravity and many spatial interaction models in a single comparative framework. Flowerdew (1982) and Willekens (1983) showed that a Poisson regression model with either row or column dummy covariates are equivalent to an origin or destination constrained spatial interaction model, and where both covariates are present, a doubly constrained spatial interaction is obtained. Such representations, with only categorical covariates, are equivalent to log-linear regression models of Birch (1963). When row or column dummy covariates are not included, but other origin- and destination-specific factors are, the resulting Poisson regression model is equivalent to a gravity model (Flowerdew, 1991).

A simplistic version of the spatial interaction model for the number of migrant in transition $n_{i j}$ from origin $i$ to destination $j$, during the respective time interval, as in each of the $R=4$ incomplete data situations of the bottom panel of Table 1, may be considered;

$$
y_{i j}=\alpha_{i} \beta_{j} m_{i j}
$$

where $y_{i j}$ is the expected number of migrants in transition from origin $i$ to destination $j$ and $i, j=1,2, \ldots, R$ for $R$ origins and destinations. The $\alpha_{i}$ and $\beta_{j}$ parameters represent the background factors that are related to the characteristics of the origin and destination. The $m_{i j}$ factor represents some axillary information on migration flows, which imposes its interaction structure into the estimated flow matrix. This is typically additional data relating to migration between the same origins and destinations. Willekens (1999) noted, in conventional spatial interaction analysis, $m_{i j}=F\left(d_{i j}\right)$ where $d_{i j}$ is a measure of distance between $i$ and $j$ and $F($.$) is a distance-deterrence function. Such distance deterrence functions can come in different$ forms, such as $F\left(d_{i j}\right)=d_{i j}^{-\epsilon}$ or $F\left(d_{i j}\right)=\exp \left(-\epsilon d_{i j}\right)$, where $\epsilon>0$ is a distance sensitivity parameter, see (Sen and Smith, 1995, p4). Alternative specifications for $m_{i j}$ might be travel costs or past migration flow matrices.

As described by Willekens (1999), the estimation of parameters in a spatial interaction model can be preformed by re-expressing the spatial interaction model in (1) in terms of a log-linear model,

$$
\log y_{i j}=\log \alpha_{i}+\log \beta_{j}+\log m_{i j},
$$

where unlike standard log-linear models, no intercept is included, and the final term is commonly referred to as an offset. The elements of $m_{i j}$ typically represent auxiliary information on migration flows that relates to the spatial interaction

The probability of observing $n_{i j}$ migrant transitions during a unit interval is given by the Poisson distribution function

$$
P\left(N_{i j}=n_{i j}\right)=\frac{y_{i j}^{n_{i j}}}{n_{i j} !} \exp \left(-y_{i j}\right)
$$


The likelihood function for $\mathbf{Y}=\left\{y_{i j}, i, j,=1, \ldots, R\right\}$ given $\mathbf{n}=\left\{n_{i j}, i, j,=1, \ldots, R\right\}$ migrant transitions, provided that migrant transitions are independent, is

$$
L(\mathbf{Y} ; \mathbf{n})=P\left(N_{11}=n_{11}, N_{12}=n_{12}, \ldots, N_{R R}=n_{R R}\right)=\prod_{i j} \frac{y_{i j}^{n_{i j}}}{n_{i j} !} \exp \left(-y_{i j}\right)
$$

Inserting the log-linear spatial model of (1) into expression (4) and taking the logarithms gives the log-likelihood function:

$$
\begin{aligned}
l(\boldsymbol{\theta} ; \mathbf{n}) & =\sum_{i j}\left\{n_{i j} \log \left(\alpha_{i} \beta_{j} m_{i j}\right)-\alpha_{i} \beta_{j} m_{i j}-\log \left(n_{i j} !\right)\right\} \\
& =\sum_{i} n_{i+} \log \left(\alpha_{i}\right)+\sum_{j} n_{+j} \log \left(\beta_{j}\right)-\sum_{i j} \alpha_{i} \beta_{j} m_{i j}+c
\end{aligned}
$$

where $\boldsymbol{\theta}=\left\{\alpha_{i}, \beta_{j}, i, j=1, \ldots, R\right\}, n_{i+}=\sum_{j} n_{i j}$ and $n_{+j}=\sum_{i} n_{i j}$ are the marginal totals, and

$$
c=\sum_{i j} n_{i j} \log \left(m_{i j}\right)-\sum_{i j} \log \left(n_{i j} !\right)
$$

The maximum likelihood estimates of $\alpha_{i}$ and $\beta_{j}$ are obtained by maximising the log-likelihood function (5). The extra term $c$, which does not involve the parameters, may be ignored. Thus, conveniently only the marginal totals from the consecutive stock tables are required to estimate the spatial interaction model.

Differentiation of the likelihood function with respect to each parameter gives the likelihood equations:

$$
\frac{\partial l}{\partial \alpha_{i}}=\frac{n_{i+}}{\alpha_{i}}-\sum_{j} \beta_{j} m_{i j}=0
$$

and

$$
\frac{\partial l}{\partial \beta_{j}}=\frac{n_{+j}}{\beta_{j}}-\sum_{i} \alpha_{i} m_{i j}=0
$$

The maximum likelihood estimators for $\alpha_{i}$ and $\beta_{j}$ can then be written as

$$
\hat{\alpha}_{i}=\frac{n_{i+}}{\sum_{j} \hat{\beta}_{j} m_{i j}}
$$

and

$$
\hat{\beta}_{j}=\frac{n_{+j}}{\sum_{i} \hat{\alpha}_{i} m_{i j}}
$$

Direct estimates of $\alpha_{i}$ and $\beta_{j}$ cannot be obtained, since there are no closed-form expressions for the solution of equation (9) and (10). However, as described in Willekens (1999), an iterative procedure can be used to derive indirect estimates. Given initial estimates of $\hat{\beta}_{j}$, Equation (9) is used to obtain initial estimates of $\hat{\alpha}_{i}$. Equation (10) is then used to update the estimates of $\beta_{j}$. This process is repeated until convergence. Maximum likelihood estimates of $y_{i j}$, the expected number of migrant transitions, can then be deduced from the converged estimates of $\hat{\alpha}_{i}$ and $\hat{\beta}_{j}$ using (1). Willekens (1999) discusses how this procedure is a special case of the iterative proportional fitting algorithm and the Expectation-Maximisation (EM) algorithm. As noted in 
Table 2: Estimates of Migrant Transition Flow Tables Based on Stock Data in Table 1 Estimates of Origin-Destination-Place of Birth Flow Tables:

\begin{tabular}{|c|c|c|c|c|c|c|}
\hline \multicolumn{7}{|c|}{ Place of Birth $=A$} \\
\hline & & \multicolumn{4}{|c|}{ Destination } & \multirow[b]{2}{*}{ Sum } \\
\hline & & A & $\mathrm{B}$ & $\mathrm{C}$ & $\mathrm{D}$ & \\
\hline \multirow{5}{*}{ క్ర్ల్ర } & A & 856 & 90 & 54 & 0 & 1000 \\
\hline & B & 86 & 9 & 5 & 0 & 100 \\
\hline & $\mathrm{C}$ & 9 & 1 & 1 & 0 & 10 \\
\hline & $\mathrm{D}$ & 0 & 0 & 0 & 0 & 0 \\
\hline & Sum & 950 & 100 & 60 & 0 & 1110 \\
\hline
\end{tabular}

Place of Birth $=B$

Place of Birth $=C$

\section{Destination}

\begin{tabular}{|c|c|c|c|c|c|}
\hline \multicolumn{6}{|c|}{ Destination } \\
\hline & A & B & $\mathrm{C}$ & $\mathrm{D}$ & Sum \\
\hline A & 7 & 42 & 6 & 0 & 55 \\
\hline B & 67 & 421 & 63 & 4 & 555 \\
\hline $\mathrm{C}$ & 6 & 38 & 6 & 0 & 50 \\
\hline $\mathrm{D}$ & 1 & 4 & 1 & 0 & 5 \\
\hline Sum & 80 & 505 & 75 & 5 & 665 \\
\hline
\end{tabular}

Place of Birth=D

\begin{tabular}{|c|c|c|c|c|c|}
\hline & $\mathrm{A}$ & B & $\mathrm{C}$ & $\mathrm{D}$ & Sum \\
\hline $\mathrm{A}$ & 8 & 3 & 67 & 3 & 80 \\
\hline B & 4 & 1 & 33 & 2 & 40 \\
\hline $\mathrm{C}$ & 75 & 25 & 667 & 33 & 800 \\
\hline $\mathrm{D}$ & 4 & 1 & 33 & 2 & 40 \\
\hline Sum & 90 & 30 & 800 & 40 & 960 \\
\hline
\end{tabular}

\begin{tabular}{|c|c|c|c|c|c|}
\hline & A & B & C & D & Sum \\
\hline $\mathrm{A}$ & 3 & 3 & 0 & 14 & 20 \\
\hline B & 4 & 4 & 0 & 17 & 25 \\
\hline $\mathrm{C}$ & 3 & 3 & 0 & 14 & 20 \\
\hline $\mathrm{D}$ & 30 & 34 & 0 & 136 & 20 \\
\hline Sum & 40 & 45 & 0 & 180 & 265 \\
\hline
\end{tabular}

Estimates of Total Origin-Destination Flow Table:

\begin{tabular}{|c|c|c|c|c|c|c|}
\hline & & & & stinat & & \\
\hline & & A & B & $\mathrm{C}$ & $\mathrm{D}$ & Sum \\
\hline & $\mathrm{A}$ & & 138 & 127 & 17 & 282 \\
\hline ह & B & 160 & & 101 & 23 & 284 \\
\hline בั & $\mathrm{C}$ & 93 & 67 & & 47 & 207 \\
\hline & $\mathrm{D}$ & 35 & 39 & 34 & & 107 \\
\hline & Sum & 287 & 244 & 262 & 87 & 881 \\
\hline
\end{tabular}

Raymer et al. (2007), this is also a conditional maximisation, otherwise known as a stepwise ascent.

For illustration, the sufficient statistics of $\mathbf{n}$ shown in Table 1 can be used derive the maximum likelihood estimates of $y_{i j}$ for each birth place specific table shown in top panel of Table 2 . To derive these estimates all elements of $m_{i j}$ were set to unity $\left(m_{i j}=1\right)$ and iterative solutions to (9) and (10) was programmed in R (R Development Core Team, 2012). Summing over all birth place dimensions and deleting non-movers in the diagonal elements allows us to obtain a traditional flow table representation of the number of migrant transitions from origin $i$ to destination $j$ within time period $t$ to $t+1$ of the bottom panel of Table 2 .

The spatial interaction model (1) focuses on estimating migrant transitions between two dimensions, origin and destination. This can be applied individually to each of the $R=4$ birth 
place specific flow tables presented in the bottom panel of Table 1. Alternatively, we can expand the model to include a third (table) dimension by adding parameters to consider all birth place specific tables simultaneously,

$$
\log y_{i j k}=\log \alpha_{i}+\log \beta_{j}+\log \lambda_{k}+\log \gamma_{i k}+\log \kappa_{j k}+\log m_{i j}
$$

where $y_{i j k}$ is the expected number of migrant transitions from origin $i$ to destination $j$ of people born in birth place $k$, during the respective time interval and $i=1,2, \ldots, R, j=1,2, \ldots, R$ and $k=1,2, \ldots, R$ for $R$ origins, destinations and birth places. The $\alpha_{i}, \beta_{j}$ and $\lambda_{k}$ parameters represent the background factors that are related to the characteristics of the origin, destination and birth place respectively. The $\gamma_{i k}$ and $\kappa_{j k}$ parameter sets represent the factors specific to each origin-birth place and destination-birth place specific combinations respectively. As in the previous model (1), estimates of all parameter sets can be obtained through solving the extended set of likelihood equations (not shown). Estimates of the fitted vales from (11) result in the identical estimates to those in Table 2, so long as each elements of the offset were again set to unity. Utilising the solutions to the likelihood equations from (11) allows the simultaneous estimation of parameters to estimate flows in all $R$ tables, rather than individually consider each, one at a time.

\subsection{Extensions for Non-Movers}

Spatial interaction models, such as those (1) and (11) have previously been used to estimate unknown cells in migration flow tables with known margins, see for example Raymer et al. (2007). However, the margins under consideration have traditionally been sums of inflows and outflows to and from of a set of regions. The marginal data in the bottom panel of Table 1 is based on a combination of movers and non movers. Hence, in order to estimate solely the migration flows an assumption about the number of non-movers in the migration system must be taken and the model adapted accordingly. Not extending a model to account for differences in non movers and migrants would effectively assume that there is the same cost to migration as there is to not migrate. One such extension is to fix the diagonal terms in each sub-table to their maximum value without violating each corresponding marginal constraints, as in Table 3. Consequently, the non-diagonal estimates will represent the minimum number of migration transitions from origin $i$ to destination $j$ between time $t$ and $t+1$ whilst maintaining marginal constraints.

In order to account for known diagonal elements in each of the sub-tables, an additional parameter can be added to (11),

$$
\log y_{i j k}=\log \alpha_{i}+\log \beta_{j}+\log \lambda_{k}+\log \gamma_{i k}+\log \kappa_{j k}+\delta_{i j k} I(i=j)+\log m_{i j},
$$

where $I(\cdot)$ is the indicator function,

$$
I(i=j)= \begin{cases}1 & \text { if } i=j \\ 0 & \text { if } i \neq j\end{cases}
$$

and the corresponding $\delta_{i j k}$ parameter set represents the factors specific to each set of nonmovers. 
Table 3: Migrant Transition Flow Tables for each Place of Birth with Assumed Non-Movers

Place of Birth=A

Destination

\begin{tabular}{|c|c|c|c|c|c|}
\hline & $\mathrm{A}$ & B & $\mathrm{C}$ & $\mathrm{D}$ & Sum \\
\hline A & 950 & & & & 1000 \\
\hline B & & 100 & & & 100 \\
\hline $\mathrm{C}$ & & & 10 & & 10 \\
\hline $\mathrm{D}$ & & & & 0 & 0 \\
\hline Sum & 950 & 100 & 60 & 0 & 1110 \\
\hline
\end{tabular}

Place of Birth $=C$

Destination

\begin{tabular}{|c|c|c|c|c|c|}
\hline & A & B & $\mathrm{C}$ & $\mathrm{D}$ & Sum \\
\hline A & 80 & & & & 80 \\
\hline$B$ & & 30 & & & 40 \\
\hline $\mathrm{C}$ & & & 800 & & 800 \\
\hline $\mathrm{D}$ & & & & 40 & 40 \\
\hline Sum & 90 & 30 & 800 & 40 & 960 \\
\hline
\end{tabular}

Place of Birth $=B$

\begin{tabular}{|c|c|c|c|c|c|}
\hline \multicolumn{6}{|c|}{ Destination } \\
\hline & $\mathrm{A}$ & B & $\mathrm{C}$ & $\mathrm{D}$ & Sum \\
\hline A & 55 & & & & 55 \\
\hline B & & 505 & & & 555 \\
\hline $\mathrm{C}$ & & & 50 & & 50 \\
\hline $\mathrm{D}$ & & & & 5 & 5 \\
\hline Sum & 80 & 505 & 75 & 5 & 665 \\
\hline
\end{tabular}

Place of Birth $=D$

\begin{tabular}{|c|c|c|c|c|c|}
\hline \multicolumn{6}{|c|}{ Destination } \\
\hline & A & B & $\mathrm{C}$ & $\mathrm{D}$ & Sum \\
\hline $\mathrm{A}$ & 20 & & & & 20 \\
\hline B & & 25 & & & 25 \\
\hline $\mathrm{C}$ & & & 0 & & 20 \\
\hline $\mathrm{D}$ & & & & 180 & 200 \\
\hline Sum & 40 & 45 & 0 & 180 & 265 \\
\hline
\end{tabular}

The log-likelihood function corresponding to the spatial interaction model in (12), where for simplicity $\delta_{i j k}$ is now referred to as $\delta_{i i k}$, is

$$
\begin{aligned}
l(\boldsymbol{\theta} ; \mathbf{n})= & \sum_{i j k}\left\{n_{i j k} \log \left(\alpha_{i} \beta_{j} \lambda_{k} \gamma_{i k} \kappa_{j k} \delta_{i i k} m_{i j}\right)-\alpha_{i} \beta_{j} \lambda_{k} \gamma_{i k} \kappa_{j k} \delta_{i i k} m_{i j}-\log \left(n_{i j k} !\right)\right\} \\
= & \sum_{i} n_{i++} \log \left(\alpha_{i}\right)+\sum_{j} n_{+j+} \log \left(\beta_{j}\right)+\sum_{k} n_{++k} \log \left(\lambda_{j}\right) \\
& +\sum_{i k} n_{i+k} \log \left(\gamma_{i k}\right)+\sum_{j k} n_{+j k} \log \left(\kappa_{j k}\right)+\sum_{i j k} n_{i j k} \log \left(\delta_{i i k}\right) \\
& -\sum_{i j k} \alpha_{i} \beta_{j} \lambda_{k} \gamma_{i k} \kappa_{j k} \delta_{i i k} \log \left(m_{i j}\right)+c
\end{aligned}
$$

where $\boldsymbol{\theta}=\left\{\alpha_{i}, \beta_{j}, \lambda_{k}, \gamma_{i k}, \kappa_{j k}, \delta_{i i k} i, j, k=1, \ldots, R\right\}, \mathbf{n}=\left\{n_{i j k}, i, j, k=1, \ldots, R\right\}$ and

$$
c=\sum_{i j k} n_{i j k} \log \left(m_{i j}\right)-\sum_{i j k} \log \left(n_{i j k} !\right)
$$

Differentiation of the likelihood function with respect to each parameter gives the likelihood 
equations:

$$
\begin{aligned}
\frac{\partial l}{\partial \alpha_{i}} & =\frac{n_{i++}}{\alpha_{i}}-\sum_{j k} \beta_{j} \lambda_{k} \gamma_{i k} \kappa_{j k} \delta_{i i k} m_{i j}=0 \\
\frac{\partial l}{\partial \beta_{j}} & =\frac{n_{+j+}}{\beta_{j}}-\sum_{i k} \alpha_{i} \lambda_{k} \gamma_{i k} \kappa_{j k} \delta_{i i k} m_{i j}=0 \\
\frac{\partial l}{\partial \lambda_{k}} & =\frac{n_{++k}}{\lambda_{k}}-\sum_{i j} \alpha_{i} \beta_{j} \gamma_{i k} \kappa_{j k} \delta_{i i k} m_{i j}=0 \\
\frac{\partial l}{\partial \gamma_{i k}} & =\frac{n_{i+k}}{\gamma_{i k}}-\sum_{j} \alpha_{i} \beta_{j} \lambda_{k} \kappa_{j k} \delta_{i i k} m_{i j}=0 \\
\frac{\partial l}{\partial \kappa_{j k}} & =\frac{n_{+j k}}{\kappa_{j k}}-\sum_{i} \alpha_{i} \beta_{j} \lambda_{k} \gamma_{i k} \delta_{i i k} m_{i j}=0 \\
\frac{\partial l}{\partial \delta_{i i k}} & =\frac{n_{i j k}}{\delta_{i i k}}-\alpha_{i} \beta_{j} \lambda_{k} \kappa_{j k} \gamma_{i k} m_{i j}=0
\end{aligned}
$$

which require only the marginal totals displayed in Table $3,\left(n_{i++}, n_{+j+}, n_{++k}, n_{i+k}\right.$ and $\left.n_{+j k}\right)$ and the diagonal values $\left(n_{i j k}\right.$, where $i=j$ ). The likelihood equations can be used to derive maximum likelihood estimators for $\hat{\boldsymbol{\theta}}=\left(\hat{\alpha}_{i}, \hat{\beta}_{j}, \hat{\lambda}_{k}, \hat{\gamma}_{i k}, \hat{\kappa}_{j k}, \hat{\delta}_{i i k}\right)$

$$
\begin{aligned}
\hat{\alpha}_{i} & =\frac{n_{i++}}{\sum_{j k} \hat{\beta}_{j} \hat{\lambda}_{k} \hat{\gamma}_{i k} \hat{\kappa}_{j k} m_{i j}} \\
\hat{\beta}_{j} & =\frac{n_{+j+}}{\sum_{i k} \hat{\alpha}_{i} \hat{\lambda}_{k} \hat{\gamma}_{i k} \hat{\kappa}_{j k} m_{i j}} \\
\hat{\lambda}_{k} & =\frac{n_{++k}}{\sum_{i j} \hat{\alpha}_{i} \hat{\beta}_{j} \hat{\gamma}_{i k} \hat{\kappa}_{j k} m_{i j}} \\
\hat{\gamma}_{i k} & =\frac{n_{i+k}}{\sum_{j} \hat{\alpha}_{i} \hat{\beta}_{j} \hat{\lambda}_{k} \hat{\kappa}_{j k} m_{i j}} \\
\hat{\kappa}_{j k} & =\frac{n_{+j k}}{\sum_{i} \hat{\alpha}_{i} \hat{\beta}_{j} \hat{\lambda}_{k} \hat{\gamma}_{i k} m_{i j}} \\
\hat{\delta}_{i i k} & =\frac{n_{i j k}}{\hat{\alpha}_{i} \hat{\beta}_{j} \hat{\lambda}_{k} \hat{\kappa}_{j k} m_{i j}}
\end{aligned}
$$

and can be solved by iteration using six steps for each parameter set:

$$
\begin{aligned}
\hat{\alpha}_{i}^{(1)} & =\frac{n_{i++}}{\sum_{j k} \hat{\beta}_{j}^{(0)} \hat{\lambda}_{k}^{(0)} \hat{\gamma}_{i k}^{(0)} \hat{\kappa}_{j k}^{(0)} \hat{\delta}_{i i k}^{(0)} m_{i j}} \\
\hat{\beta}_{j}^{(2)} & =\frac{n_{+j+}}{\sum_{i k} \hat{\alpha}_{i}^{(1)} \hat{\lambda}_{k}^{(0)} \hat{\gamma}_{i k}^{(0)} \hat{\kappa}_{j k}^{(0)} \hat{\delta}_{i i k}^{(0)} m_{i j}} \\
\hat{\lambda}_{k}^{(3)} & =\frac{n_{++k}}{\sum_{i j} \hat{\alpha}_{i}^{(1)} \hat{\beta}_{j}^{(2)} \hat{\gamma}_{i k}^{(0)} \hat{\kappa}_{j k}^{(0)} \hat{\delta}_{i i k}^{(0)} m_{i j}} \\
\hat{\gamma}_{i k}^{(4)} & =\frac{n_{i+k}}{\sum_{j} \hat{\alpha}_{i}^{(1)} \hat{\beta}_{j}^{(2)} \hat{\lambda}_{k}^{(3)} \hat{\kappa}_{j k}^{(0)} \hat{\delta}_{i i k}^{(0)} m_{i j}} \\
\hat{\kappa}_{j k}^{(5)} & =\frac{n_{+j k}}{\sum_{i} \hat{\alpha}_{i}^{(1)} \hat{\beta}_{j}^{(2)} \hat{\lambda}_{k}^{(3)} \hat{\gamma}_{i k}^{(4)} \hat{\delta}_{i i k}^{(0)} m_{i j}}
\end{aligned}
$$




$$
\hat{\delta}_{i i k}^{(6)}=\frac{n_{i j k}}{\hat{\alpha}_{i}^{(1)} \hat{\beta}_{j}^{(2)} \hat{\lambda}_{k}^{(3)} \hat{\gamma}_{i k}^{(4)} \hat{\kappa}_{j k}^{(5)} m_{i j}} .
$$

Once one cycle of estimation is complete, a new cycle commences using the last set of parameter estimates, $\hat{\alpha}_{i}^{(6)}=n_{i++} / \sum_{j k} \hat{\beta}_{j}^{(2)} \hat{\lambda}_{k}^{(3)} \hat{\gamma}_{i k}^{(4)} \hat{\kappa}_{j k}^{(5)} \hat{\delta}_{i i k}^{(6)} m_{i j}$, and so on. Again this is a conditional maximization of the likelihood function and converges to give estimates of all the parameters in $\boldsymbol{\theta}$. Note that the choice of initial values of $\beta_{j}^{(0)}, \lambda_{k}^{(0)}, \gamma_{i k}^{(0)}, \kappa_{j k}^{(0)}, \delta_{i i k}^{(0)}$ in each of (16) implicitly specifies the constraint that is required for parameter identification.

Maximum likelihood estimates of $y_{i j k}$ can then be obtained from the converged estimates of $\hat{\boldsymbol{\theta}}$ using equation (12). The sufficient statistics of $\mathbf{n}$ shown in Table 3 can be used again to derive the maximum likelihood estimates of $y_{i k j}$, the expected number of migrant transitions.

Table 4: Estimates of Migrant Transition Flow Tables Based on Stock Data in Table 1, with Known Diagonals

Estimates of Origin-Destination-Place of Birth Flow Tables:

Place of Birth=A

Destination

\begin{tabular}{|c|c|c|c|c|c|}
\hline & A & B & $\mathrm{C}$ & $\mathrm{D}$ & Sum \\
\hline A & 950 & 0 & 50 & 0 & 1000 \\
\hline B & 0 & 100 & 0 & 0 & 100 \\
\hline $\mathrm{C}$ & 0 & 0 & 10 & 0 & 10 \\
\hline $\mathrm{D}$ & 0 & 0 & 0 & 0 & 0 \\
\hline Sum & 950 & 100 & 60 & 0 & 1110 \\
\hline
\end{tabular}

Place of Birth $=C$

\section{Destination}

\begin{tabular}{|c|c|c|c|c|c|}
\hline & A & B & $\mathrm{C}$ & $\mathrm{D}$ & Sum \\
\hline $\mathrm{A}$ & 80 & 0 & 0 & 0 & 80 \\
\hline B & 10 & 30 & 0 & 0 & 40 \\
\hline $\mathrm{C}$ & 0 & 0 & 800 & 0 & 800 \\
\hline $\mathrm{D}$ & 0 & 0 & 0 & 40 & 40 \\
\hline Sum & 90 & 30 & 800 & 40 & 960 \\
\hline
\end{tabular}

Place of Birth=B

Destination

\begin{tabular}{|c|c|c|c|c|c|}
\hline & A & B & C & D & Sum \\
\hline $\mathrm{A}$ & 55 & 0 & 0 & 0 & 55 \\
\hline $\mathrm{B}$ & 25 & 505 & 25 & 0 & 555 \\
\hline $\mathrm{C}$ & 0 & 0 & 50 & 0 & 50 \\
\hline $\mathrm{D}$ & 0 & 0 & 0 & 5 & 5 \\
\hline Sum & 80 & 505 & 75 & 5 & 665 \\
\hline
\end{tabular}

Place of Birth $=D$

Destination

\begin{tabular}{|c|c|c|c|c|c|}
\hline & $\mathrm{A}$ & B & $\mathrm{C}$ & $\mathrm{D}$ & Sum \\
\hline A & 20 & 0 & 0 & 0 & 20 \\
\hline B & 0 & 25 & 0 & 0 & 25 \\
\hline $\mathrm{C}$ & 10 & 10 & 0 & 0 & 20 \\
\hline $\mathrm{D}$ & 10 & 10 & 0 & 180 & 200 \\
\hline Sum & 40 & 45 & 0 & 180 & 265 \\
\hline
\end{tabular}

Estimates of Total Origin-Destination Flow Table:

\begin{tabular}{|c|c|c|c|c|c|c|}
\hline & & & & ina & & \\
\hline & & A & B & $\mathrm{C}$ & D & Sum \\
\hline & A & & 0 & 50 & 0 & 50 \\
\hline ह & B & 35 & & 25 & 0 & 60 \\
\hline בֶ. & $\mathrm{C}$ & 10 & 10 & & 0 & 20 \\
\hline & $\mathrm{D}$ & 10 & 10 & 0 & & 20 \\
\hline & Sum & 55 & 20 & 75 & 0 & 150 \\
\hline
\end{tabular}


To obtain these estimates all elements of $m_{i j}$ were set to unity $\left(m_{i j}=1\right)$ and iterative solutions to (16) were programmed in $\mathrm{R}$ ( $\mathrm{R}$ Development Core Team, 2012). The results are displayed in the top panel of Table 4. Summing over all birth place dimensions and deleting non-movers in the diagonal elements allows us to obtain a traditional flow table of migrant transitions from origin $i$ to destination $j$ during the time period $t$ to $t+1$ in the bottom panel of Table 4. Estimated migrant transitions are now considerably smaller that those of Table 2. This is due to the extension in model (12) to incorporating information, via additional parameters for assumed diagonal elements, that the distribution of non moving population and migrant transition flows between the $t$ and $t+1$ is no longer independent.

\subsection{Extensions to Include Births, Deaths and Flows to Outside Regions}

In reality, natural changes from births and deaths in the population occur, causing differences in the row totals of the stock data between subsequent years. In addition, migrants can move to or from regions outside those under initial consideration. We will consider each of these three sources of population change in this sub-section using a new set of hypothetical data for $t+1$, displayed in Table 5, where differences between row totals exist. In each case, population stocks that form the margins of the birth place specific flow tables must be adjusted to enable the row and column margins to equal. This is carried out through a four step procedure.

Table 5: Dummy Example of Place of Birth Data

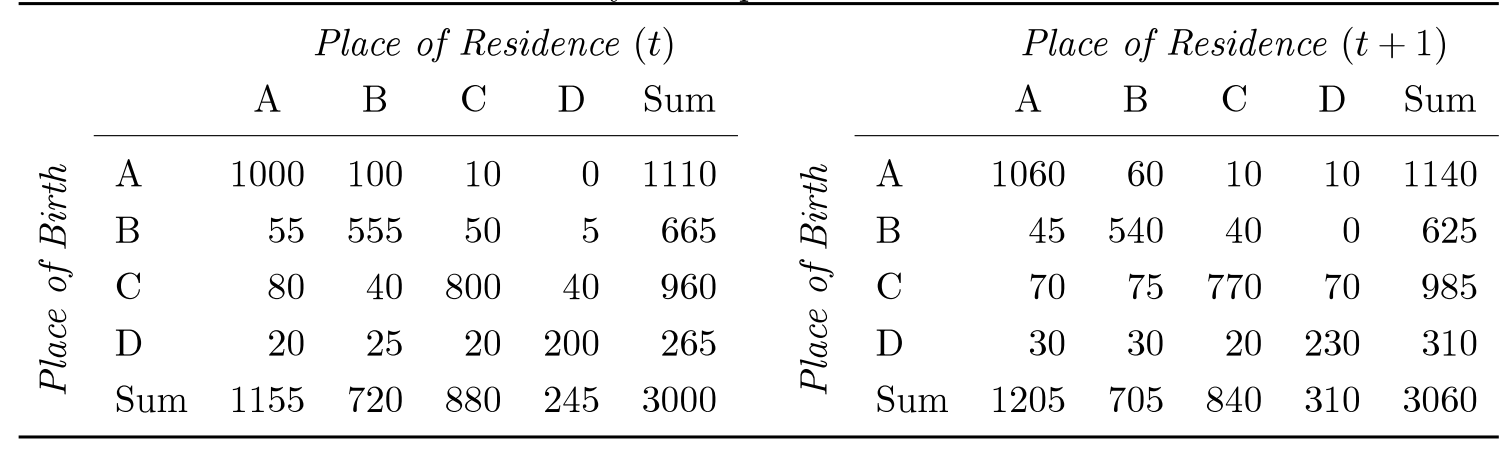

First, alterations are made to the stock tables to account for sources of natural population change. In order to avoid estimating migrant transitions to meet decreases in stock totals from mortality, the number of deaths in the time interval $t$ to $t+1$ must be subtracted from the reported stock data at time $t$. Typically only the total number of deaths in each place of residence is known, whilst a decomposition of the numbers of deaths by place of birth is missing. To estimate this breakdown, and hence adjust each native and foreign born population stocks, we proportionally allocate out the total number of deaths to each population stock. This is demonstrated on the left hand side of Step 1 in Table 6, where the total number of deaths, given in bold type face in the final sum row, are known. These totals are proportionally split according to the reported population stocks in time $t+1$, to provide estimates of the number of deaths by each place of birth.

In order to avoid estimating migration flows to meet increases in native born totals from newborns, the number of births between $t$ and $t+1$ must be subtracted from the reported stock data at time $t+1$. As with deaths, we tend to only have information on the total number of 
Table 6: Multi-Step Correction to Stock Data

Step 1: Control for Natural Changes

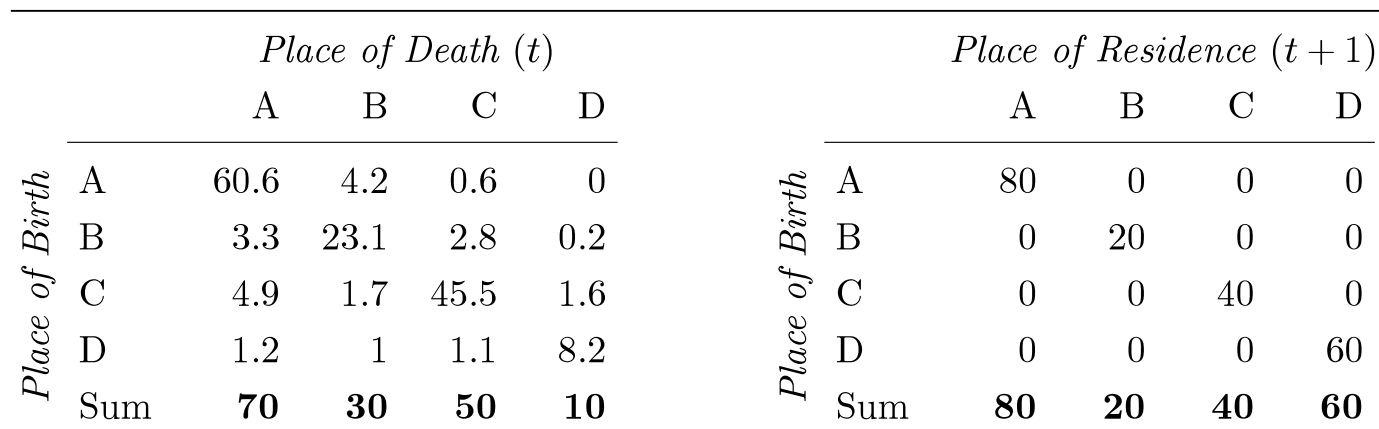

Step 2: Estimated Altered Stocks

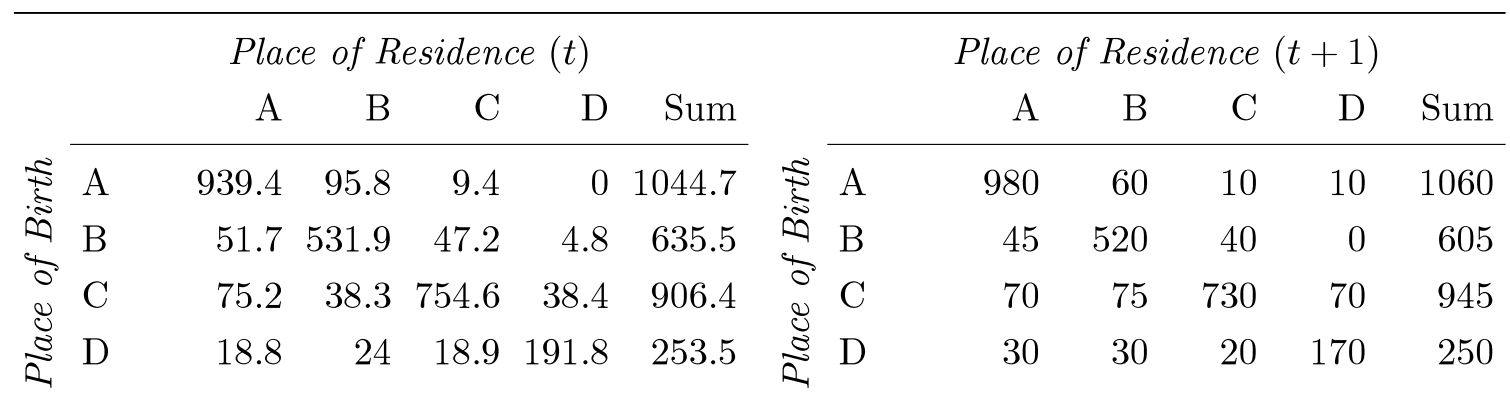

Step 3: Estimate Flows to External Regions

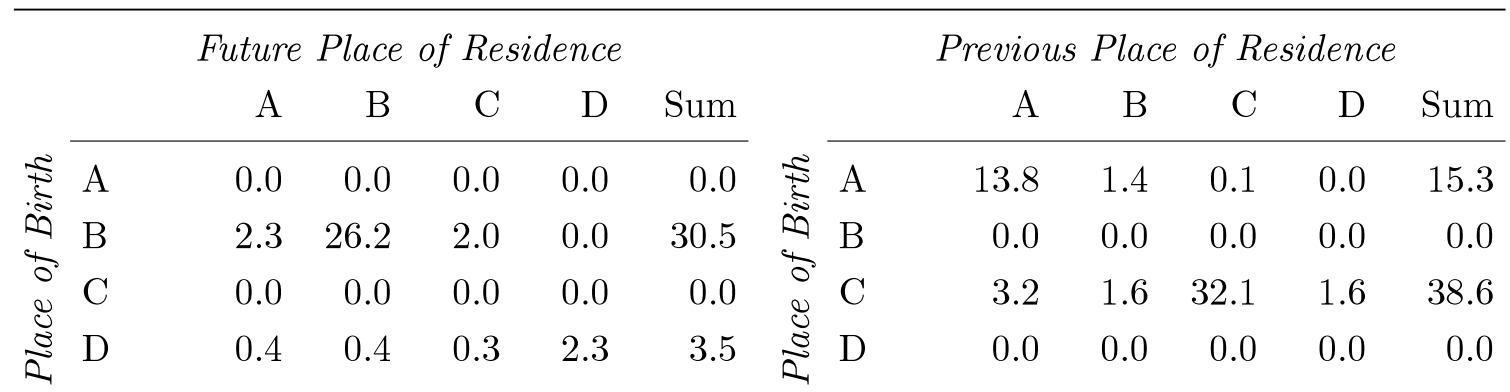

Step 4: Re-estimated Altered Stocks

\begin{tabular}{|c|c|c|c|c|c|c|c|c|c|c|c|c|c|}
\hline & & Pla & ce of $R$ & esiden & $c e(t)$ & & & & Place & of Res & idence & $(t+1)$ & \\
\hline & & A & B & $\mathrm{C}$ & $\mathrm{D}$ & Sum & & & A & B & $\mathrm{C}$ & $\mathrm{D}$ & Sum \\
\hline & $\mathrm{A}$ & 939.4 & 30.0 & 9.4 & 0 & 1044.7 & $\widetilde{5}$ & $\mathrm{~A}$ & 966.2 & 58.6 & 9.9 & 10.0 & 1044.7 \\
\hline & B & 49.4 & 505.7 & 45.1 & 4.8 & 605.0 & 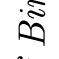 & B & 45.0 & 520.0 & 40.0 & 0 & 605.0 \\
\hline 3 & $\mathrm{C}$ & 75.2 & 38.3 & 754.6 & 38.4 & 906.4 & 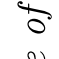 & $\mathrm{C}$ & 66.8 & 73.4 & 697.9 & 68.4 & 906.4 \\
\hline & $\mathrm{D}$ & 18.4 & 23.5 & 18.6 & 189.5 & 250.0 & $\underset{\widetilde{J}}{\mathbb{Z}}$ & $\mathrm{D}$ & 30.0 & 30.0 & 20.0 & 170.0 & 250.0 \\
\hline & Sum & 1082.3 & 663.4 & 827.7 & 232.7 & 2806.1 & & Sum & 1108.0 & 682.0 & 767.7 & 248.4 & 2806.1 \\
\hline
\end{tabular}

births, where ideally we desire more detail on the place of residence of newborns at time $t+1$. In order to adjust stock totals for natural increases, we restrict births to only affect the native born stocks, assuming there is no migration of newborns. This is demonstrated on the right hand side of Step 1 in Table 6, where the total number of births, given in bold type face in 
the final sum row, are known. These totals of newborns are allocated to reside in their place of birth at time $t+1$.

A new set of adjusted stock tables that account for natural population change are then calculated. These are shown in Step 2 of Table 6, where both the death and birth estimates of the previous step are subtracted cell-wise from the original data in Table 5. The new altered stock totals still do not have equal row totals. If our estimates (and assumptions) about the changes to population stocks from natural causes are true, the remaining differences between the row totals in the altered stock tables must represent the minimum amount of migrant transitions to or from outside external regions beyond A to D. When this difference is greater than zero, i.e. the row totals for in time period $t+1$ is greater than $t$, migrants have arrived from external regions. When this difference is less than zero, i.e. the row totals for in time period $t+1$ is smaller than $t$, migrants have moved away to external regions. Adjustments must be made for these differences in order to estimate migration solely within regions under consideration (A to D).

To illustrate the estimation of migrant transition flows to and from external regions, consider Step 2 of Table 6 where the adjusted stock of people originally born in region A were 1044.66 and 1060 in time $t$ and $t+1$ respectively. Note, fractions of migrants are given only to fully illustrate the mathematics at work. As the difference is negative $(-15.34)$, the stock of people originally born in region A has fallen, after accounting for the natural population change. This difference provides us with information on the total number of people originally born in region A that moved to an external region between time $t$ and $t+1$. These emigrants might reside in any place of residence at time $t$. In order to estimate this breakdown we proportionally allocate out the 15.34 external migrants. This is demonstrated on the right hand side of Step 3 in Table 6 for both region A and C, where proportions are calculated according to the reported population stocks in time $t$. Conversely, when the difference in row totals of altered stocks are positive, such as for those in region B in Step 2 of Table 6, we have information on the total number of people originally born in region $\mathrm{B}$ that moved back from an external region between time $t$ and $t+1$. These immigrants might have arrived into any place of residence. The migrant transition flows are estimated by proportional allocation, shown on the left hand side of Step 3 in Table 6 for both region B and D. Proportions are calculated according to the reported population stocks in time $t+1$.

In Step 4 of Table 6 we re-estimate the altered stock totals to adjust for migration flows to and from external regions. These are calculated by subtracting cell-wise the previous adjusted stock totals in Step 2 from the calculated flows to other regions in Step 3. The resulting stock tables control for both changes in natural population change and moves to and from external regions during the time period $t$ to $t+1$. In addition they have matching row totals, required to estimate flows using the methodology outlined in the previous subsection.

The sufficient statistics of $\mathbf{n}$ shown in Stage 4 of Table 6 can be consdierd as a set of $R=4$ birth place specific flow tables, shown in the margins in the top panel of Table 7. These suffient statistics can then be used to derive the maximum likelihood estimates of he expected number of migrant transitions $\left(y_{i j k}\right)$, having accounted for changes in stock totals shown in Table 5 from natural change and moves to and from external regions, shown in the cells of each birth place specific table in the top panel of Table 7. Again, all elements of the offset term $m_{i j}$ 
Table 7: Estimates of Migrant Transition Flow Tables Based on Stock Data Derived in Table 6, with Known Diagonals

Estimates of Origin-Destination-Place of Birth Flow Tables:

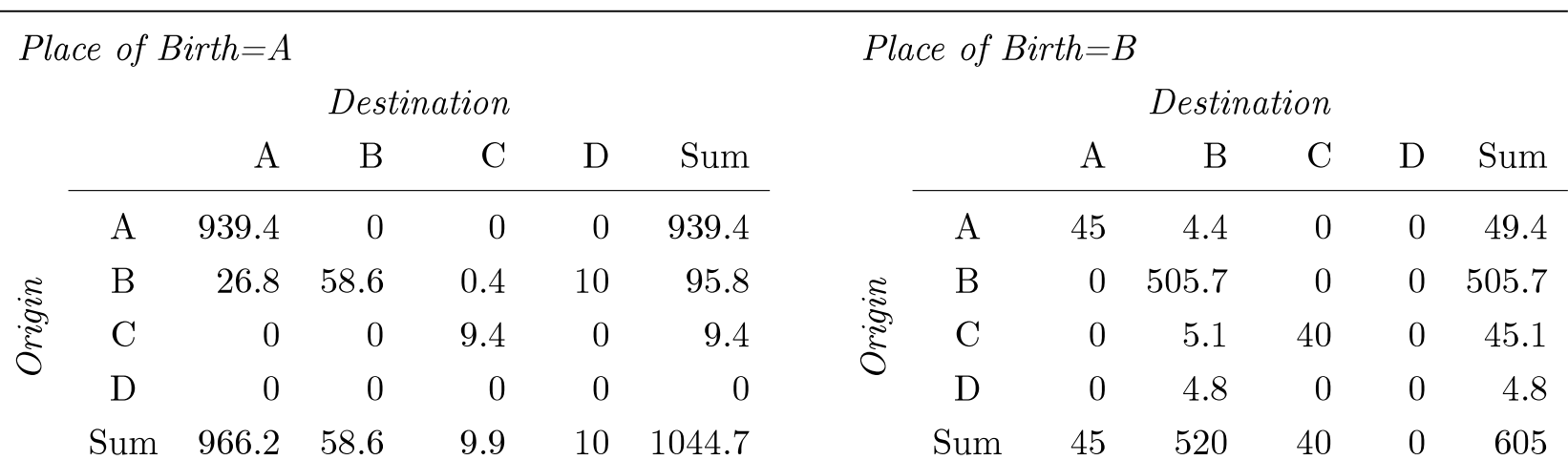

Place of Birth $=C$

Place of Birth=D

\begin{tabular}{|c|c|c|c|c|c|}
\hline \multicolumn{6}{|c|}{ Destination } \\
\hline & $\mathrm{A}$ & B & C & $\mathrm{D}$ & Sum \\
\hline $\mathrm{A}$ & 66.8 & 4.5 & 0 & 3.9 & 75.2 \\
\hline B & 0 & 38.3 & 0 & 0 & 38.3 \\
\hline $\mathrm{C}$ & 0 & 30.5 & 697.9 & 26.2 & 754.6 \\
\hline $\mathrm{D}$ & 0 & 0 & 0 & 38.4 & 38.4 \\
\hline Sum & 66.8 & 73.4 & 697.9 & 68.4 & 906.4 \\
\hline
\end{tabular}

\begin{tabular}{crrrrr}
\multicolumn{7}{c}{ Destination } \\
& A & B & C & D & Sum \\
\hline A & 18.4 & 0 & 0 & 0 & 18.4 \\
B & 0 & 23.5 & 0 & 0 & 23.5 \\
C & 0 & 0 & 18.6 & 0 & 18.6 \\
D & 11.6 & 6.5 & 1.4 & 170 & 189.5 \\
Sum & 30 & 30 & 20 & 170 & 250
\end{tabular}

Estimates of Total Origin-Destination Flow Table:

\begin{tabular}{|c|c|c|c|c|c|c|}
\hline \multicolumn{7}{|c|}{ Destination } \\
\hline \multirow{6}{*}{ క్స్ } & & $\mathrm{A}$ & $\mathrm{B}$ & $\mathrm{C}$ & $\mathrm{D}$ & Sum \\
\hline & $\mathrm{A}$ & & 9 & 0 & 4 & 13 \\
\hline & $\mathrm{B}$ & 27 & & 0 & 10 & 37 \\
\hline & $\mathrm{C}$ & 0 & 36 & & 26 & 62 \\
\hline & $\mathrm{D}$ & 12 & 11 & 1 & & 24 \\
\hline & Sum & 38 & 56 & 2 & 40 & 136 \\
\hline
\end{tabular}

are set to unity and the diagonal element were set to their maximum possible values given the known margins. Summing over all birth place dimensions and deleting non-movers in the diagonal elements allows us to obtain the traditional flow table in the bottom panel of Table 7. Estimates are not directly comparable with previous flow tables as they are formed from a different set of migrant stock data in $t+1$.

\section{Results}

In this section the application of the above methodology to global place of birth migrant stock tables produced by the World Bank (Özden et al., 2011) is outlined, alongside the additional 
data requirements. A brief overview of the results, focusing on the largest estimated flows is then discussed.

\subsection{Application}

Place of birth data published by the World Bank (Özden et al., 2011) provide foreign born migration stock tables at the start of each of the last five decades for 226 countries. To date, this is the most complete set of comparable global data of past international migration stocks available. Data is primarily based on place of birth responses to Census questions or details collected from population registers. For some nations, where there are no place of birth data available, data on citizenship are taken with the belief that they are broadly equivalent measures. In other countries where neither measure were available, missing values were addressed using various propensity and interpolation methods. These were either based on historical or future data when a measure in a specific period was missing, or using available data from countries in the same region when data in all periods were missing. Changes in geography, from countries unifying or partitioning were also accounted on a country by country basis using various imputation measures depending on available related data. For example, historical stocks by place of birth in former USSR countries were not collected in the 1960 to 1980 census rounds, however questions were asked on ethnicity. In the 1989 census both stocks by ethnicity and place of birth data were reported, allowing a proxy measure of past place of birth stocks to be derived.

Of the 226 countries for which data was available, 191 were selected where demographic data required for controlling the flow estimation for natural population change, was readily available from the United Nations Population Division (2011). None of the dropped countries had a populations in 2010 in excess 100,000 people. Diagonal elements in each stock table, of the native-born population totals in each place of residence $j,\left(P_{j}^{N B}\right)$, are not provided in the World Bank data. These were derived as a remainder $\left(P_{j}^{N B}=P_{j}-\sum_{i} P_{j}^{F B}\right)$ using annual population totals from the United Nations Population Division (2011), $\left(P_{j}\right)$ and the column sums of the foreign born populations in each place of residence $\left(\sum_{i} P_{j}^{F B}\right)$. This procedure constrained the column totals of the stock tables to meet those of the reported populations at the start of each decade.

Demographic data on the number of births and deaths in each country, required in the multi-step estimation shown in Table 6, were also taken from United Nations Population Division (2011). Auxillary data for use in the offset term of the estimation procedure were taken from the Centre d'Etudes Prospective et d'Informations Internationales (CEPII) data base on geographic distance (Mayer and Zignago, 2012), which provides a distance measure between all capital cities. The offset term was then calculated as $m_{i j}=d_{i j}^{-1}$. The multi-step accounting method was undertaken to adjust reported stock totals for births, deaths and flows to external countries beyond the 191 considered. The conditional maximisation routine was then run to calculate the migration flow tables for each decade between the five sets of migration stock tables. 


\subsection{Summary of Estimates}

The application of the estimation procedure resulted in four $191 \times 191$ flow tables (see http: //g00.gl/B291D for a spreadsheet of these estimates). Compressed tables, aggregated over World Bank regions (used in Özden et al. (2011)) are shown in Table 8 to Table 11. Non-diagonal elements in these tables represent rounded thousands of estimated 10 year international migrant transition flows between regions. Diagonal elements represent estimated 10 year international migrant transition flows within regions. As per standard migration flow tables, rows represent origins and columns destinations.

Estimates of the total volume of migrant transition flows increase over time, reflecting global population growth. However, in both the 1970's and 1980's estimated flows between all countries was steady at around 42 million. The most popular origins of flows over the entire time period, by estimated volume, were in Eastern Europe and Central Asia (EECA), and in the later tables, Latin America and the Caribbean (LAC). Most destinations of those in the EECA region tended to be to other countries also within the EECA region, where as the flows out fo LAC tended to go to other regions, most notably the USA. Large migrant transition flows are estimated from Western Europe (WE) and South Asia (SA) regions in the 1960's and 1970's tables respectively. The majority of these large flows are to other nations in the same region. The most popular destinations of flows over the entire time period, by estimated volume, were into the USA and WE. The largest sending regions into the USA were from East Asia and the Pacific (EAP) and LAC. The largest flows into WE came from the east (EECA) and other WE nations.

Results can also be studied on a country by country bases from the full migrant transition flow tables. The USA received the highest estimated migrant transition inflows of any country in almost every decade (top of Table 12). Germany was also a large receiver of estimated inflows throughout each decades studied, whilst the United Kingdom and France were also top receivers in the 1990's. France received the largest inflow of all nations in the 1960's. Large migrant inflows to France during this decade were estimated to originate from Algeria, Italy, Spain and Portugal. Russia and the Ukraine also received large number of estimated immigrants in all decades with exception of the 1970's. India and Pakistan both received large estimated inflows during the 1970's as did Saudi Arabia in the 1980's.

Russia was a top origin for estimated migrant transition outflows in each of the first three decades (bottom of Table 12), as was the Ukraine and Kazakhstan in the 1980's and 1990's respectively. The majority of these outflows are to other former USSR countries. For example, the large outflows from Kazakhstan in the 1990's are estimated to meet a large increase in the Kazakhstan-born stocks in Russia (1.8 to 2.5 million). This stock change also contributes to the large inflow in the 1990's into Russia, shown in the top of Table 12, alongside large flows from other former USSR countries such as Uzbekistan, Ukraine and Azerbaijan. These estimates are derived to meet the changes in the World Bank stock data, which were themselves estimates. Other nations in the former USSR and Indian sub-continent also have large estimated migration outflows over the decades, which might partly reflect on changes in the estimates in the World Bank stock data (rather than raw data from Censuses or registers).

Mexico was a predominant sender in the later decades, with large amounts of estimated flows into the USA. France appears as large sender of estimated outflows in both the 1960's and 
Table 8: 1960's Estimated Global Migrant Transition Flow (in 1000's) Table Aggregated Over 12 World Bank Regions.

\begin{tabular}{lrrrrrrrrrrrrrr}
\hline & AFR & ANZ & CAN & EAP & EECA & GFNA & JPN & LAC & MENA & SA & USA & WE & Sum \\
\hline AFR & 2392 & 30 & 39 & 10 & 4 & 22 & 0 & 13 & 7 & 76 & 33 & 650 & 3277 \\
ANZ & 3 & 31 & 0 & 24 & 7 & 0 & 0 & 1 & 0 & 0 & 11 & 29 & 107 \\
CAN & 3 & 9 & 0 & 1 & 16 & 1 & 0 & 9 & 0 & 0 & 43 & 49 & 132 \\
EAP & 30 & 52 & 119 & 2152 & 16 & 26 & 84 & 13 & 4 & 132 & 313 & 79 & 3018 \\
EECA & 31 & 97 & 45 & 7 & 6729 & 143 & 0 & 13 & 39 & 2 & 50 & 1485 & 8642 \\
GFNA & 5 & 3 & 5 & 0 & 4 & 45 & 0 & 5 & 124 & 3 & 22 & 6 & 222 \\
JPN & 1 & 2 & 1 & 49 & 1 & 0 & 0 & 9 & 0 & 0 & 50 & 4 & 118 \\
LAC & 19 & 84 & 165 & 11 & 18 & 9 & 4 & 553 & 2 & 1 & 1665 & 517 & 3048 \\
MENA & 158 & 30 & 41 & 8 & 42 & 516 & 0 & 28 & 390 & 22 & 45 & 1535 & 2813 \\
SA & 105 & 15 & 61 & 193 & 5 & 232 & 2 & 2 & 70 & 1896 & 61 & 223 & 2864 \\
USA & 17 & 43 & 59 & 19 & 123 & 17 & 8 & 186 & 8 & 1 & 0 & 423 & 904 \\
WE & 300 & 638 & 241 & 143 & 266 & 78 & 5 & 148 & 27 & 22 & 309 & 4962 & 7137 \\
Sum & 3064 & 1032 & 774 & 2617 & 7231 & 1089 & 104 & 978 & 672 & 2156 & 2603 & 9962 & 32283 \\
\hline
\end{tabular}

$\mathrm{AFR}=$ Africa, $\mathrm{ANZ}=$ Australia and New Zealand, $\mathrm{CAN}=$ Canada, $\mathrm{EAP}=$ East Asia and the Pacific,

EECA = Eastern Europe and Central Asia, GFNA = High Income Middle East and North Africa, JPN = Japan, LAC = Latin America and the Caribbean, MENA = Rest of Middle East and North Africa, SA = South Asia, $\mathrm{USA}=$ United States, WE $=$ Western Europe

Table 9: 1970's Estimated Global Migrant Transition Flow (in 1000's) Table Aggregated Over 12 World Bank Regions.

\begin{tabular}{lrrrrrrrrrrrrr}
\hline & AFR & ANZ & CAN & EAP & EECA & GFNA & JPN & LAC & MENA & SA & USA & WE & Sum \\
\hline AFR & 2882 & 53 & 40 & 8 & 5 & 148 & 0 & 17 & 11 & 13 & 126 & 742 & 4046 \\
ANZ & 9 & 122 & 7 & 6 & 17 & 3 & 0 & 3 & 0 & 1 & 30 & 53 & 254 \\
CAN & 12 & 14 & 0 & 2 & 17 & 5 & 1 & 5 & 1 & 1 & 117 & 69 & 244 \\
EAP & 14 & 186 & 154 & 2786 & 13 & 251 & 120 & 33 & 4 & 103 & 1445 & 458 & 5566 \\
EECA & 15 & 59 & 40 & 4 & 4734 & 159 & 0 & 4 & 38 & 1 & 44 & 2278 & 7376 \\
GFNA & 16 & 3 & 11 & 3 & 39 & 100 & 0 & 2 & 165 & 14 & 80 & 93 & 527 \\
JPN & 0 & 3 & 1 & 10 & 0 & 0 & 0 & 10 & 1 & 1 & 156 & 34 & 216 \\
LAC & 38 & 50 & 172 & 6 & 28 & 10 & 6 & 1019 & 3 & 0 & 3109 & 800 & 5241 \\
MENA & 80 & 53 & 44 & 6 & 22 & 1252 & 0 & 12 & 577 & 8 & 273 & 996 & 3322 \\
SA & 33 & 36 & 69 & 40 & 4 & 1194 & 2 & 3 & 246 & 8020 & 200 & 345 & 10193 \\
USA & 57 & 25 & 142 & 6 & 216 & 42 & 2 & 177 & 11 & 3 & 0 & 498 & 1178 \\
WE & 218 & 210 & 169 & 30 & 226 & 65 & 4 & 57 & 16 & 4 & 568 & 2347 & 3915 \\
Sum & 3375 & 813 & 847 & 2908 & 5321 & 3230 & 137 & 1343 & 1074 & 8168 & 6148 & 8712 & 42077 \\
\hline
\end{tabular}

$\mathrm{AFR}=$ Africa, $\mathrm{ANZ}=$ Australia and New Zealand, CAN = Canada, EAP = East Asia and the Pacific,

EECA = Eastern Europe and Central Asia, GFNA = High Income Middle East and North Africa, JPN = Japan, $\mathrm{LAC}=$ Latin America and the Caribbean, MENA = Rest of Middle East and North Africa, SA = South Asia, $\mathrm{USA}=$ United States, WE $=$ Western Europe 
Table 10: 1980's Estimated Global Migrant Transition Flow (in 1000's) Table Aggregated Over 12 World Bank Regions.

\begin{tabular}{lrrrrrrrrrrrrr}
\hline & AFR & ANZ & CAN & EAP & EECA & GFNA & JPN & LAC & MENA & SA & USA & WE & Sum \\
\hline AFR & 2636 & 79 & 70 & 14 & 19 & 269 & 6 & 24 & 24 & 34 & 173 & 643 & 3990 \\
ANZ & 1 & 100 & 24 & 6 & 14 & 4 & 4 & 3 & 1 & 10 & 15 & 67 & 249 \\
CAN & 4 & 7 & 0 & 2 & 20 & 9 & 2 & 5 & 3 & 5 & 217 & 57 & 330 \\
EAP & 7 & 421 & 226 & 1264 & 8 & 519 & 182 & 32 & 10 & 93 & 2143 & 500 & 5406 \\
EECA & 5 & 34 & 58 & 11 & 8040 & 455 & 1 & 7 & 76 & 11 & 58 & 2980 & 11737 \\
GFNA & 5 & 11 & 19 & 4 & 61 & 244 & 1 & 5 & 309 & 30 & 79 & 148 & 916 \\
JPN & 0 & 10 & 6 & 15 & 1 & 1 & 0 & 1 & 0 & 0 & 105 & 35 & 173 \\
LAC & 20 & 60 & 340 & 13 & 37 & 34 & 56 & 826 & 4 & 3 & 5055 & 692 & 7142 \\
MENA & 23 & 47 & 38 & 6 & 46 & 1597 & 1 & 17 & 668 & 13 & 211 & 865 & 3531 \\
SA & 23 & 56 & 70 & 96 & 11 & 2201 & 12 & 4 & 638 & 860 & 383 & 394 & 4749 \\
USA & 12 & 18 & 141 & 33 & 94 & 42 & 19 & 97 & 10 & 15 & 0 & 230 & 711 \\
WE & 120 & 181 & 283 & 47 & 843 & 116 & 13 & 153 & 38 & 57 & 269 & 1450 & 3571 \\
Sum & 2858 & 1025 & 1275 & 1509 & 9192 & 5492 & 298 & 1174 & 1782 & 1131 & 8710 & 8061 & 42505 \\
\hline
\end{tabular}

$\mathrm{AFR}=$ Africa, $\mathrm{ANZ}=$ Australia and New Zealand, $\mathrm{CAN}=$ Canada, $\mathrm{EAP}=$ East Asia and the Pacific,

EECA = Eastern Europe and Central Asia, GFNA = High Income Middle East and North Africa, JPN = Japan, LAC = Latin America and the Caribbean, MENA = Rest of Middle East and North Africa, SA = South Asia, $\mathrm{USA}=$ United States, WE $=$ Western Europe

Table 11: 1990's Estimated Global Migrant Transition Flow (in 1000's) Table Aggregated Over 12 World Bank Regions.

\begin{tabular}{lrrrrrrrrrrrrr}
\hline & AFR & ANZ & CAN & EAP & EECA & GFNA & JPN & LAC & MENA & SA & USA & WE & Sum \\
\hline AFR & 3941 & 84 & 117 & 19 & 21 & 140 & 5 & 10 & 23 & 20 & 391 & 875 & 5646 \\
ANZ & 6 & 121 & 10 & 60 & 16 & 7 & 6 & 4 & 1 & 0 & 41 & 145 & 417 \\
CAN & 21 & 28 & 0 & 38 & 28 & 21 & 9 & 39 & 5 & 2 & 246 & 236 & 674 \\
EAP & 41 & 427 & 678 & 2818 & 55 & 134 & 394 & 51 & 50 & 8 & 2096 & 687 & 7438 \\
EECA & 10 & 54 & 90 & 77 & 6726 & 621 & 5 & 18 & 90 & 1 & 826 & 5057 & 13575 \\
GFNA & 8 & 12 & 41 & 28 & 31 & 229 & 0 & 2 & 413 & 63 & 70 & 99 & 997 \\
JPN & 1 & 15 & 13 & 43 & 2 & 0 & 0 & 2 & 2 & 0 & 86 & 57 & 221 \\
LAC & 34 & 22 & 240 & 42 & 107 & 43 & 240 & 1043 & 7 & 0 & 8064 & 1584 & 11426 \\
MENA & 27 & 46 & 136 & 29 & 74 & 571 & 6 & 10 & 704 & 82 & 267 & 584 & 2536 \\
SA & 58 & 106 & 344 & 367 & 13 & 1136 & 17 & 6 & 70 & 715 & 850 & 891 & 4572 \\
USA & 23 & 20 & 13 & 56 & 39 & 51 & 11 & 213 & 27 & 2 & 0 & 271 & 727 \\
WE & 235 & 40 & 131 & 63 & 719 & 122 & 13 & 86 & 122 & 7 & 410 & 3928 & 5876 \\
Sum & 4403 & 977 & 1811 & 3639 & 7832 & 3076 & 707 & 1484 & 1515 & 900 & 13347 & 14413 & 54105 \\
\hline
\end{tabular}

$\mathrm{AFR}=$ Africa, $\mathrm{ANZ}=$ Australia and New Zealand, CAN $=$ Canada, EAP $=$ East Asia and the Pacific,

EECA = Eastern Europe and Central Asia, GFNA = High Income Middle East and North Africa, JPN = Japan, LAC = Latin America and the Caribbean, MENA = Rest of Middle East and North Africa, SA = South Asia, $\mathrm{USA}=$ United States, WE $=$ Western Europe 
Table 12: Countries with the 5 Largest Estimated 10-year Migrant Transition Inflows (top) and Outflows (bottom).

\begin{tabular}{lrlrlrlr}
\hline Country & 1960 's & Country & 1970 's & Country & 1980 's & Country & 1990 's \\
\hline FRA & $3,151,489$ & USA & $6,148,134$ & USA & $8,709,721$ & USA & $13,346,816$ \\
USA & $2,602,511$ & IND & $4,975,291$ & RUS & $3,356,465$ & RUS & $5,082,317$ \\
DEU & $2,531,999$ & PAK & $2,893,128$ & SAU & $3,065,083$ & DEU & $3,738,591$ \\
UKR & $1,749,508$ & DEU & $2,708,104$ & DEU & $2,215,946$ & FRA & $2,873,948$ \\
RUS & $1,741,571$ & HKG & $1,984,883$ & UKR & $1,477,474$ & GBR & $1,819,267$ \\
& & & & & & & \\
Country & 1960 's & Country & 1970 's & Country & 1980 's & Country & 1990 's \\
\hline \multirow{2}{*}{ RUS } & $3,086,746$ & BGD & $4,800,661$ & RUS & $2,655,499$ & MEX & $5,037,273$ \\
HKG & $1,500,636$ & IND & $4,066,949$ & MEX & $2,446,505$ & IND & $2,594,894$ \\
PAK & $1,440,894$ & RUS & $2,117,101$ & IND & $2,403,785$ & FRA & $2,586,883$ \\
ITA & $1,285,555$ & TUR & $1,774,873$ & UKR & $1,507,850$ & CHN & $1,643,347$ \\
FRA & $1,243,313$ & CHN & $1,693,328$ & DEU & $1,354,946$ & KAZ & $1,605,811$ \\
\hline
\end{tabular}

FRA $=$ France, $\mathrm{DEU}=$ Germany, UKR $=$ Ukraine, RUS $=$ Russia, $\mathrm{IND}=$ India, PAK $=$ Pakistan, HKG $=$ Hong Kong, SAU $=$ Saudi Arabia, GBR $=$ Great Britain, ITA $=$ Italy, BGD $=$ Bangladesh, TUR $=$ Turkey, CHN $=$ China, MEX $=$ Mexico, KAZ = Kazakhstan

1990's. In the 1960's the outflow was driven predominately by migrants born in Poland (their stock falls from 474,000 to 280,000 between the start and end of the decade). In the 1990's the outflow is driven by migrants from Portugal and Spain returning to their place of birth (their stock falls from 609,000 and 429,000 to 141,000 and 151,000 respectively between the start and end of the decade). Germany has a large outflow of migrants in the 1980's. The largest estimated flow from Germany in this decade is to the Czech Republic, to match a large fall in the number of Czech born migrants (from around 750,000 in 1980 to 375,000 in 1990). World Bank stock data for Germany, as with the former USSR nations were estimated, as no place of birth data were available. The large outflows from Turkey in the 1970's were also influenced by the stock data in Germany, where the number of Turkish born rose from around 440,000 in 1970 to 1.65 million in 1980. Large outflows from China in the 1990's were to the USA and Hong Kong. The appearance of China and Hong Kong as large senders in earlier decades might be due to stock data peculiarities discussed below.

Estimated values can be further explored by studying the place of birth dimension, alongside the origin and destination of migration flows. For example, considering the USA as a destination, the largest estimated inflows by origin and place of birth in each decade are shown Table 13. Estimates show that throughout the four time periods large flows originate from countries in Latin America (Mexico, Cuba, and Puerto Rico) and Asia (Philippines, Korea, Vietnam, India and China). In addition, we can garner further information on place of birth of these migrants, which can also hint at questionable estimates generated from changes in stock data over time. For example, during the 1960's there are is a large flow into the USA from Hong Kong of people born in China. This flow is a result partly of a rise in the Chinese born in the USA stock data between 1960 and 1970 (from around 100,000 to 220,000) and partly from a peculiarity of the 
Hong Kong data. In 1960 there were a reported 1.5 million Chinese born in Hong Kong. This stock drops to 16,823 in 1970 and rises back up to almost 1.9 million in 1980. This dramatic movement in the reported stocks creates a large estimated outflow of Chinese in the 1960's. These emigrants are moving to countries where there are increases in the number of Chinese born, including but not exclusively, China. In turn, during the 1970's there is a large inflow back into Hong Kong of Chinese born, to meet the sudden increase in their foreign born stock.

Table 13: Countries with the 5 Largest Estimated 10-year Migrant Transition Inflows to the USA by Origin and Place of Birth.

\begin{tabular}{|c|c|c|c|c|c|c|c|}
\hline Origin & Destination & Place of Birth & 1960's & Origin & Destination & Place of Birth & 1970's \\
\hline CUB & USA & CUB & 439,346 & MEX & USA & MEX & $1,556,421$ \\
\hline MEX & USA & MEX & 402,118 & PHL & USA & PHL & 361,425 \\
\hline PRI & USA & PRI & 343,996 & KOR & USA & KOR & 231,073 \\
\hline PHL & USA & PHL & 142,902 & PRI & USA & PRI & 212,880 \\
\hline HKG & USA & $\mathrm{CHN}$ & 85,868 & CUB & USA & CUB & 208,657 \\
\hline Origin & Destination & Place of Birth & 1980's & Origin & Destination & Place of Birth & 1990's \\
\hline MEX & USA & MEX & $2,399,422$ & MEX & USA & MEX & $4,910,358$ \\
\hline PHL & USA & PHL & 495,993 & PHL & USA & PHL & 54,1725 \\
\hline SLV & USA & SLV & 407,537 & IND & USA & IND & 500,653 \\
\hline KOR & USA & KOR & 383,622 & VNM & USA & VNM & 437,534 \\
\hline VNM & USA & VNM & 329,061 & $\mathrm{CHN}$ & USA & $\mathrm{CHN}$ & 411,763 \\
\hline
\end{tabular}

$\mathrm{CUB}=$ Cuba, MEX $=$ Mexico, $\mathrm{PRI}=$ Puerto Rico, $\mathrm{HKG}=$ Hong Kong, $\mathrm{PHL}=$ Philippines, $\mathrm{KOR}=$ South Korea, $\mathrm{SLV}=$ Slovenia, $\mathrm{VNM}=$ Vietnam, $\mathrm{IND}=$ India, $\mathrm{CHN}=$ China

\section{Validation of Results}

Due to the large amount of data estimated, some form of dimension reduction is required in order to asses estimates beyond looking at compressed tables of regional flows and the top inflows and outflows. In this section the estimated migration transition flows from the applied methodology are discussed with reference to comparable estimates of global net migration flows of the United Nations and models for international migration.

\subsection{Net Migration Comparison}

The United Nations Population Division (2011) published net migration flows for each member country over a five-year period. These data are based predominately on scaled annual flows, derived from either migration records or through demographic accounting. In order to get a 10 year net migration flow, to correspond to the estimated 10-year migration transition, the two 5-year net migrations totals for each decade (one for the first half of a decade and one for the second half) were summed for each country. A net rate was then calculated using the mid-decade years population totals and multiplying by 1000 . Comparative net migration rates 
Figure 1: Scatter Plot of Estimated Net 10-year Migrant Transition Flow Rates vs Derived UN Rates (per 000)

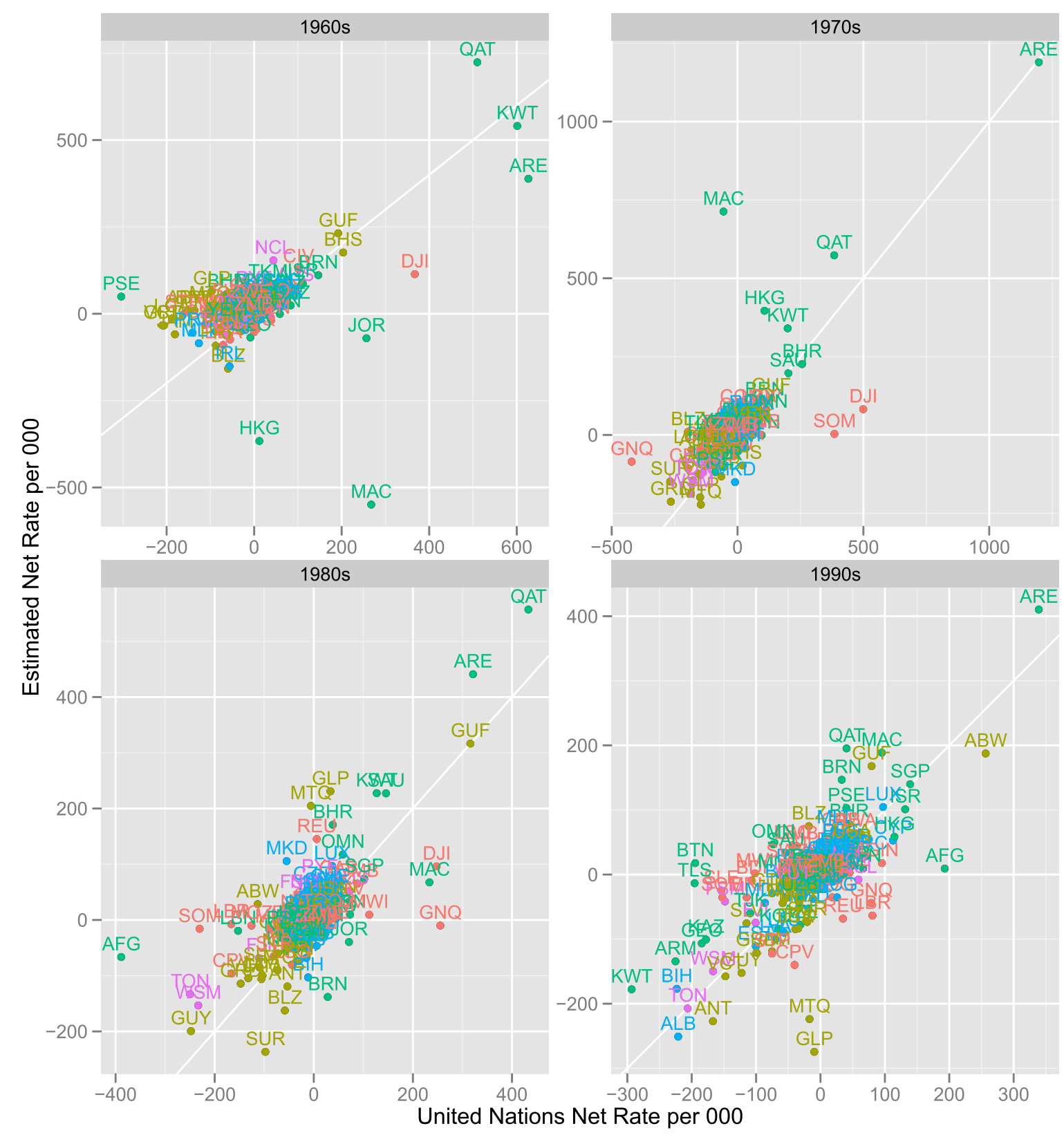

from the estimates were calculated by taking the total inflow away from total outflow in each country, divided by the mid-decade years population totals and multiplying by 1000 . A scatter plot comparing the estimated net rates (on the y-axis) with the derived United Nations net rate (x-axis) by decade is shown in Figure 1 from each decade. Noticeable is the general linear trend along the $x=y$ line, indicating a broad conformity of the estimated with the derived UN net rates. This pattern is confirmed in separate regressions of the estimated rate on the derived United Nations rate and an intercept for each decade, shown in Table 14. Parameters were estimated in R using the rlm function from the MASS package (Venables and Ripley, 2002) to account for outliers (discussed later). 
Table 14: Regression of Derived United Nations (UN) Net Rates on Estimated Net Rates.

\begin{tabular}{lcccc}
\hline Parameter (Std. Error) & 1960 's & 1970 's & 1980 's & 1990 's \\
\hline Intercept & 2.19803 & -0.33207 & -1.05609 & -1.52908 \\
& $(1.76241)$ & $(1.92035)$ & $(1.90238)$ & $(2.27249)$ \\
UN Net Rate & 0.53494 & 0.74672 & 0.64345 & 0.66924 \\
& $(0.01721)$ & $(0.01508)$ & $(0.02244)$ & $(0.02919)$ \\
\hline
\end{tabular}

Intercept values are within two standard deviations of zero, suggesting there is no constant effect of the United Nations net rates being significantly different than the estimated net rates in any of the four time periods. The slope coefficients are all positive, but less than unity, indicating the estimated net rates values are lower than the derived United Nations net rate. This result is not unexpected for three reasons. First, the United Nations net figures are based on timing definitions for migration during an interval that is less than 10-years. Subsequently more migrant transitions are recorded from moves over the periods of time. This difference is compounded when a 10-year net was derived. Second, the estimated 10-year migration tables represent transitions and not movements. Hence, multiple movements of a migrant might potentially be recorded by the United Nations over a five-year period, where only one transition comparing the location of the migrant at the start and end of the period is considered in the net rate based on the estimated flow tables. Third, the estimated data from the stock to flow methodology are the minimal migration flow transitions in each decade required to meet the World Bank stock data. This minimum was derived by setting the diagonal values in each place of birth table to their maximum value as illustrated in the methodology section.

Outliers with high positive net migration are captured by both the estimated and the United Nations rate, such as the United Arab Emirates (ARE), Kuwait (KWT) and Quatar (QAT). Other outliers such as Hong Kong (HKG) and Macau (MAC) show a disagreement between the United Nations rate and the rate from the estimated bilateral flow table. As discussed previously, the estimated bilateral flows are subject to peculiarities in the World Bank stock data. Similar data peculiarities also occurred over time for the stock of people born in Martinique (MTQ) and Guadalupe (GLP) residence in France. Countries such as Jordan (JOR), Djibouti (DJI) and Somalia (SOM) have large derived positive United Nations net migration rates in either the 1960 's, 1970's or 1980's, where the net rate from the estimated bilateral flow table is generally closer to zero, not accounting for the short term refugee movements between neighbouring countries.

\subsection{Gravity Model}

Kim and Cohen (2010) investigated non-economic predictors of reported international migration bilateral flows. Using a log normal regression model, geographic, demographic and social and historical determinants were estimated twice, once using migration flow data by origin into 17 destinations countries and using migration flow data by destinations from 13 origin countries. Flow data was taken from a time series of migration flow data by the United Nations Population Division (2009), which contains a collection of unharmonised sending and receiving flow data reported by developed nations. Data for covariates were obtained from United Nations 
Table 15: Model Parameters of M1 in Kim and Cohen (2010) on Logarithm of Estimated Flows.

\begin{tabular}{|c|c|c|c|c|c|c|}
\hline \multirow{2}{*}{$\begin{array}{l}\text { Parameter } \\
\text { Constant }\end{array}$} & \multicolumn{2}{|c|}{$\begin{array}{c}\text { Estimate } \\
\text { (Std. Error) }\end{array}$} & \multicolumn{2}{|c|}{$\begin{array}{c}\text { K\&C Receiving } \\
\text { (Std. Error) }\end{array}$} & \multicolumn{2}{|c|}{$\begin{array}{c}\text { K\&C Sending } \\
\text { (Std. Error) }\end{array}$} \\
\hline & 2.271 & $(0.141)$ & -9.960 & $(0.231)$ & -12.408 & $(0.258)$ \\
\hline \multicolumn{7}{|l|}{ Demographic determinants } \\
\hline Log population (destination) & 0.206 & $(0.007)$ & 0.601 & $(0.009)$ & 0.372 & $(0.008)$ \\
\hline Log population (origin) & 0.423 & $(0.007)$ & 0.728 & $(0.006)$ & 0.936 & $(0.011)$ \\
\hline Log potential support ratio (destination) & -0.166 & $(0.055)$ & -0.811 & $(0.069)$ & -0.052 & $(0.024)$ \\
\hline Log potential support ratio (origin) & -0.027 & $(0.054)$ & 0.045 & $(0.020)$ & 0.915 & $(0.079)$ \\
\hline Log infant mortality rate (destination) & -0.704 & $(0.017)$ & 1.007 & $(0.049)$ & -0.783 & $(0.016)$ \\
\hline Log infant mortality rate (origin) & -0.083 & $(0.017)$ & -0.466 & $(0.013)$ & 0.359 & $(0.054)$ \\
\hline Log percentage of urban population (destination) & 0.239 & $(0.018)$ & 3.057 & $(0.072)$ & 0.307 & $(0.021)$ \\
\hline Log percentage of urban population (origin) & 0.163 & $(0.017)$ & 0.332 & $(0.017)$ & 2.578 & $(0.077)$ \\
\hline \multicolumn{7}{|l|}{ Geographical determinants } \\
\hline Log distance between capitals & -1.026 & $(0.010)$ & -0.819 & $(0.011)$ & -0.660 & $(0.012)$ \\
\hline Log land area (destination) & 0.210 & $(0.005)$ & 0.234 & $(0.008)$ & 0.146 & $(0.007)$ \\
\hline Log land area (origin) & 0.047 & $(0.006)$ & -0.047 & $(0.005)$ & 0.030 & $(0.009)$ \\
\hline Landlocked (destination) & -0.073 & $(0.010)$ & -0.610 & $(0.040)$ & -0.086 & $(0.011)$ \\
\hline Landlocked (origin) & -0.104 & $(0.010)$ & -0.170 & $(0.009)$ & -1.043 & $(0.038)$ \\
\hline Border & 0.737 & $(0.023)$ & 0.077 & $(0.022)$ & 0.096 & $(0.024)$ \\
\hline \multicolumn{7}{|l|}{ Social and historical determinants } \\
\hline Common official language & 0.264 & $(0.015)$ & 0.138 & $(0.014)$ & 0.346 & $(0.027)$ \\
\hline $9 \%$ minority speak same language & 0.325 & $(0.015)$ & 0.266 & $(0.014)$ & 0.003 & $(0.027)$ \\
\hline Colony & 0.686 & $(0.026)$ & 0.427 & $(0.017)$ & 0.747 & $(0.023)$ \\
\hline Year - 1985 & -0.013 & $(0.001)$ & 0.008 & $(0.001)$ & 0.001 & $(0.001)$ \\
\hline$(\text { Year }-1985)^{2}$ & 0.000 & $(0.000)$ & 0.000 & $(0.000)$ & -0.000 & $(0.000)$ \\
\hline
\end{tabular}

Population Division (2011) for demographic measures on population, potential support ratio (PSR), infant mortality rate (IMR) and urbanisation, and the CEPII for geographic and social data on distances, language and colonial relationships (Mayer and Zignago, 2012).

In this section, the same initial model used in Kim and Cohen (2010) is fitted (once) to the logarithm of estimated bilateral flows between the 191 origin and destination countries. Following the same procedures, estimated migration flows with value zero were excluded and logarithms with base 10 were used throughout. In addition, mid-decade values were taken for time varying covariate measures. The estimated parameters and standard errors are shown in Table 15 alongside the parameters obtained by Kim and Cohen (2010) when the model was fitted to the receiving data (K\&C Receiving) and sending data (K\&C Sending). Standard regression diagnostics suggested there were no major problems with the model assumptions. What follows is a brief discussion of the parameter estimates, and comparisons with the results found by the two model fits of Kim and Cohen (2010). For further clarification on the expected direction and justification of variable constructions and selection, the reader is refereed to Kim and Cohen (2010). 
The constant parameter value from the fit on the estimated data is considerably higher than that found in Kim and Cohen (2010). This reflects the greater average size of the estimated 10 year migration transition flows compared to the collection of reported flow data from the United Nations, which for example has no information on flows within Asia, Africa, Latin America, much of Eastern Europe, in the Indian subcontinent and the former USSR. The population parameters for both the origin and destination countries are greater than zero, indicating that as the population in an origin or destination increases, the expected logarithm of the estimated migration flow also increases, when all other variables are held constant. These parameters are both smaller in size than those found from the two models fitted to the reported flow data. Parameter estimates for both the effect of the PSR and IMR are all negative, indicating that as they increase in value, the estimated migration flow decreases. For the PSR this result is slightly counter-intuitive; the higher the working-age population as a fraction of the origin or destination population, the lower the expected international migration. This result is less important for migration to origins where the parameter value is relatively close to zero when the standard error is considered. For destinations, similar results were found in both models based no the receiving and sending data in Kim and Cohen (2010). For the IMR, negative parameters suggest that at higher levels of infant mortality in either origin or destination the number of expected migration flows is lower. For destinations this effect is large, indicating that ceteris paribus a destination with a high IMR is expected to have fewer immigrants. For origins this effect is relatively close to zero, again indicating slightly counter-intuitively that an origin with a high IMR is expected to have less emigrants. The percentages of urban population in destination and origin increased the migration flows in and out of countries respectability, as expected.

For geographic determinants, both distance and an indicator variable for border sharing had large effects on the expected migration flow, especially in comparison with the Kim and Cohen (2010) parameters. Unsurprisingly the distance parameter is very close to negative one, as the same information was used in the offset term of (12) for the estimation of stocks from flows. Other geographic parameters on land area and landlocked follow the intuitive results found by Kim and Cohen (2010); larger countries send and receive more migration flows, whist landlocked countries have lower migration due to higher transportation costs.

All social and historical dichotomous variables have positive values. Hence, where there is a shared language, shared minority languages or colonial link between origin and destination, the model parameters indicate there was an increase in the expected flow of migration. Finally, the linear and quadratic time parameters are relatively close to zero, indicating only small effects of increases in migration when other time varying covariates are controlled for in the model.

\section{Summary and Discussion}

In this paper, a methodology to estimate global migrant transition flow tables is illustrated in two parts. First, a methodology to derive flows from sequential stock tables was outlined. Second, the methodology was applied to recently released World Bank migration stock tables to estimate a set of four de'cadal global flow tables. The results of the applied methodology were discussed with reference to comparable estimates of global net migration flows of the United 
Nations and previous models for international migration flows.

The methodology outlined adds to the limited previous literature on linking migration flows to stocks. Rogers and von Rabenau (1971) and Rogers and Raymer (2005) focused on US Census place of birth data to estimate inter-state migration transitions. The first of these papers relies on a simplistic principal assumption of equal growth of stock totals in all regions. As a result, the application of the method outlined to the World Bank data produced many strange results, including negative migration flows. The second of these papers relies on aggregated stock populations by their place of birth, place of residence at time $t-1$ and place of residence at time $t$. This added dimension of required data negates its application to estimating international migration flows.

The method for estimating migrant transition flows from stocks demonstrated in this paper constrains results to match those of known sequential stock tables. This approach is beneficial for a number of reasons. First, comparable migration stock data are easier to measure and collect at a global level than flow data. Difficulties in producing comparable international migration flow data has recently lead to a number of competing estimation efforts, all applied to European data, see for example Abel (2010); Beer et al. (2010); Raymer et al. (2012). However, these methodologies rely on a reasonable percentage of double counted flows, i.e., reported values of a movements from both the sending and receiving counties. The application of these estimation methods to obtain global migration flow data is hindered by the availability of reported migration flows, which from non-European countries remains scarce. Second, as discovered in the results section of this paper, estimating stocks from flows can provide a good check on the stock data itself. The flow estimation method is partly reliant on the differential change in the stock data. When this change is large, big flows are estimated. Where these flow estimates are unexpected, peculiarities in the data can be quickly identified. Third, estimating flow required to match stock totals results in migrant transitions rather than movement events. Transition measures can be of particular use in global population projection models, such as those outlined by Cohen et al. (2008). Projection models tend to require migration transitions that match the age groups at which the future population is predicted. For example, the results presented in this paper could potentially be incorporated into a projection models that age populations at 10-year intervals. If denser intervals are desired, such as five-year or single year age intervals, new estimates would be required. These could be derived in one of two ways. Stock tables in non-census years could be estimated to create a larger set of sequential stock tables (within the same time frame) allowing flows between closer time periods to be obtained. Alternatively, one could use a method such as that outlined by Courgeau (1973) to convert 10-year estimates to shorter periods. If such estimates were derived, they could potentially be compared with flow data from countries who have a Census question on the place of residence one or five year prior to their Census night, forming another conceivable validation exercise.

The estimated flow tables are a first-of-a-kind set of comparable global origin destination flow data. Estimates represent the minimum number of migration transition flows required to meet the foreign born stocks. Results from both validation exercises appeared promising. They also allowed, as did the brief overview of the main results, the identification of unexpected flows. For most case, further investigation of these unexpected results were driven by large changes in the input stock data. In other cases the methodology could be further expanded in number of 
different ways to address the causes of these unexpected flows.

Estimated flows were minimised by making an additional assumption on the number of non-movers. Empirical evidence, where available, could be utilised to reduce the diagonal element, producing more migration flows to and from a selected country. Discrepancies in the total number of two sequential stock tables were first altered to account for natural population change. Remaining differences were assumed to be due to moves to or from external countries not studied. In reality, in the application of the methodology the majority of these differences were most likely due to measurement issues in the stock data from some counties. The methodology could be expanded to incorporate measures of under or over counting of stocks, where known, to reduce the amount of external moves that are proportionally allocated. The World Bank stock data were taken to represent the foreign born stock totals at the start of each decade. In reality, data was actually collected over a number of years around each census period. Corrections for stock data that allow estimates of foreign born stocks at one point of time for all countries might further reduce some of the unexpected flow estimates. Changes in stocks from natural population change were controlled for using rather crude methods. More detailed data is likely to exist in some counties on the mortality by place of birth of foreign born migrants that may negate the need to distribute the total number of deaths proportionally. In addition, the estimation of the place of residence of newborns could be further developed to allow moves outside their country of birth in these early years. Finally, the log-linear models with an offset have been used to estimate missing internal migration flow data. Alternative auxiliary data, to the distance measure used in this paper, could be utilised within the methodology outlined.

In conclusion, comparable international migration flow data are needed by researchers to better understand peoples movements and identify patterns. Policy makers can also use comparable international migration flow data to help forecast populations better, where migration can often play an important role. The methodology outlined in this paper provides a relatively simple yet powerful technique to estimate global migration flow tables, exploiting newly available global stock data. 


\section{References}

Abel, G. J. (2010). Estimation of international migration flow tables in Europe. Journal of the Royal Statistical Society: Series A (Statistics in Society) 173(4), 797-825.

Beer, J., J. Raymer, R. Erf, and L. Wissen (2010, November). Overcoming the Problems of Inconsistent International Migration data: A New Method Applied to Flows in Europe. European Journal of Population/Revue européenne de Démographie 26 (4), 459-481.

Bilsborrow, R. E., G. Hugo, A. S. Oberai, and H. Zlotnik (1997). International Migration Statistics: Guidelines for Improvement of Data Collection Systems (First ed.). Geneva, Switzerland: International Labour Office.

Birch, M. W. (1963). Maximum Likelihood in Three-Way Tables. Journal of the Royal Statistical Society, Series B 25, 220-233.

Cohen, J. E., M. Roig, D. C. Reuman, and C. Gogwilt (2008, October). International migration beyond gravity: A statistical model for use in population projections. Proceedings of the National Academy of Sciences 105(40), 15269-15274.

Courgeau, D. (1973). Migrants et migrations. Population (French Edition).

Flowerdew, R. (1982). Fitting the Lognormal Gravity Model to Heteroscedastic Data. Geographical Analysis 14(3), 263-267.

Flowerdew, R. (1991). Poisson Regression Models Of Migration. In J. Stillwell and P. Congdon (Eds.), Migration Models: Macro and Micro Approaches., Chapter 6, pp. 92-113. London, England: Belhaven Press.

Fotheringham, A. S. and M. E. O'Kelly (1988, December). Spatial Interaction Models:Formulations and Applications (Ispra Courses on Remote Sensing) (1 ed.). Springer.

Goldstein, S. (1976, November). Facets of redistribution: research challenges and opportunities. Demography 13(4), 423-434.

Henning, S. and B. Hovy (2011). Data Sets on International Migration. International Migration Review 45(4), 980-985.

K.C., S., B. Barakat, A. Goujon, V. Skirbekk, W. Sanderson, and W. Lutz (2010). Projection of populations by level of educational attainment, age, and sex for 120 countries for 2005-2050. Demographic Research 22(55), 383-472.

Kelly, J. J. (1987). Improving the Comparability of International Migration Statistics: Contributions by the Conference of European Statisticians from 1971 to Date. International Migration Review 21(4), 1017-1037.

Kim, K. and J. E. Cohen (2010). Determinants of International Migration Flows to and from Industrialized Countries: A Panel Data Approach Beyond Gravity1. International Migration Review 44(4), 899-932. 
Kupiszewski, M. and D. Kupiszewska (2008). International migration component in population dynamics models. In J. Raymer and F. Willekens (Eds.), International Migration in Europe, Chapter 14, pp. 309-327. Chichester, United Kingdom: Wiley.

Mayer, T. and S. Zignago (2012, January). Notes on CEPII's Distances Measures: The GeoDist Database. Social Science Research Network Working Paper Series.

Nowok, B., D. Kupiszewska, and M. Poulain (2006). Statistics on International Migration Flows. In M. Poulain, N. Perrin, and A. Singleton (Eds.), Towards the Harmonisation of European Statistics on International Migration (THESIM), Chapter 8, pp. 203-233. Louvain-La-Neuve, Belguim: UCL-Presses Universitaires de Louvain.

Özden, c., C. R. Parsons, M. Schiff, and T. L. Walmsley (2011, March). Where on Earth is Everybody? The Evolution of Global Bilateral Migration 19602000. World Bank Economic Review, 12-56.

R Development Core Team (2012). R: A Language and Environment for Statistical Computing. Vienna, Austria: R Foundation for Statistical Computing.

Raymer, J., G. J. Abel, and P. W. F. Smith (2007, October). Combining census and registration data to estimate detailed elderly migration flows in England and Wales. Journal of the Royal Statistical Society: Series A (Statistics in Society) 170(4), 891-908.

Raymer, J., J. J. Forster, P. W. F. Smith, J. Bijak, and A. Wiśniowski (2012). Integrated Modelling of European Migration: Background, Specification and Results. NORFACE Migration Discussion Paper (4).

Rees, P. and F. Willekens (1986). Data and Accounts. In F. Willekens and A. Rogers (Eds.), Migration and Settlement: A Multiregional Comparative Study, Chapter 2, pp. 19-58. Dordrecht, Netherlands: D. Reidel Publishing Company.

Rees, P. H. (1980). Multistate demographic accounts: measurement and estimation procedures. Environment and Planning A 12, 499-531.

Rogers, A. (1990). Requiem for the Net Migrant. Geographical Analysis 22.

Rogers, A. (1995). Multiregional Demography: Principles, Methods and Extensions (1 ed.). John Wiley \& Sons.

Rogers, A. and J. Raymer (2005, March). Origin dependence, secondary migration, and the indirect estimation of migration flows from population stocks. Journal of Population Research 22(1), 1-19.

Rogers, A. and B. von Rabenau (1971, May). Estimation of interregional migration streams from place-of-birth-by-residence data. Demography 8(2), 185-194.

Salt, J. (1993). Migration and population change in Europe. Technical Report 19UNIDIR/93/23, United Nations Institute for Disarmament Research, (UNIDIR), New York, New York. 
Sen, A. K. and T. E. Smith (1995). Gravity Models of Spatial Interaction Behavior (Advances in Spatial and Network Economics). New York, USA: Springer-Verlag.

Stewart, J. Q. (1941). An Inverse Distance Variation For Certain Social Influences. Science 93(2404), 89-90.

United Nations General Assembly (2011, March). Resolution adopted by the General Assembly. In International migration and development, Volume 67 of 65 th Session. United Nations.

United Nations Population Division (2009). International Migration Flows to and from Selected Countries: The 2008 Revision.

United Nations Population Division (2011). World Population Prospects: The 2010 Revision, Highlights and Advance Tables. Working Paper ESA/P/WP (220).

Venables, W. N. and B. D. Ripley (2002, September). Modern applied statistics with $S$ (4th ed.). New York, USA: Springer.

Willekens, F. (1983). Log-Linear Modelling Of Spatial Interaction. Papers in Regional Science 52(1), 187-205.

Willekens, F. (1994, March). Monitoring international migration flows in Europe. European Journal of Population/Revue européenne de Démographie 10(1), 1-42.

Willekens, F. (1999). Modeling Approaches to the Indirect Estimation of Migration Flows: From Entropy to EM. Mathematical Population Studies 7(3), 239-78.

Wilson, A. G. (1970). Entropy in Urban and Regional Modelling. London, United Kingdom: Pion.

Zipf, G. K. (1942). The Unity of Nature, Least Action, and Natural Social Science. Sociometry $5(1), 48-62$. 


\section{VIENNA INSTITUTE OF DEMOGRAPHY}

\section{Working Papers}

Ediev, Dalkhat M., At Modal Age at Death, the Hazard Rate is Determined by its Derivative, VID Working Paper 08/2011.

Zeman, Kryštof, Tomáš Sobotka, Richard Gisser, Maria Winkler-Dworak, and Wolfgang Lutz, Geburtenbarometer Vienna: Analysing Fertility Convergence between Vienna and Austria, VID Working Paper 07/2011 (English and German versions available).

Feichtinger Gustav, Michael Kuhn, Alexia Prskawetz, and Stefan Wrzaczek, The Reproductive Value as Part of the Shadow Price of Population, VID Working Paper 06/2011.

Barakat, Bilal, Time is Money: Could Deferred Graduate Retirement Finance Higher Education?, VID Working Paper 05/2011.

Riosmena, Fernando, Maria Winkler-Dworak, Alexia Prskawetz, and Gustav Feichtinger, The Impact of Policies Influencing the Demography of Age Structured Populations: Lessons from Academies of Science, VID Working Paper 04/2011.

Buber, Isabella and Katrin Fliegenschnee, Are you Ready for a Child? A Methodological Triangulation on Fertility Intentions in Austria, VID Working Paper 03/2011.

Fent, Thomas, Belinda Aparicio Diaz, and Alexia Prskawetz, Family Policies in the Context of Low Fertility and Social Structure, VID Working Paper 02/2011.

Buber, Isabella, Caroline Berghammer, and Alexia Prskawetz, Doing Science, Forgoing Childbearing? Evidence from a Sample of Female Scientists in Austria, VID Working Paper 01/2011.

Strulik, Holger, Klaus Prettner, and Alexia Prskawetz, R\&D-Based Growth in the Post-Modern Era, VID Working Paper 09/2010.

Prettner, Klaus and Alexia Prskawetz, Demographic Change in Models of Endogenous Economic Growth. A Survey, VID Working Paper 08/2010.

Flandorfer, Priska, Christian Wegner, and Isabella Buber, Gender Roles and Smoking Behaviour, VID Working Paper 07/2010.

Barakat, Bilal, Johannes Holler, Klaus Prettner, and Julia Schuster, The Impact of the Economic Crisis on Labour and Education in Europe, VID Working Paper 06/2010.

The Vienna Institute of Demography Working Paper Series receives only limited review. Views or opinions expressed herein are entirely those of the authors. 